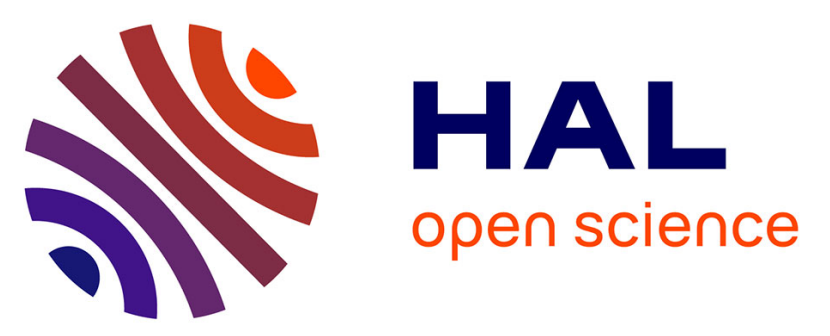

\title{
Indole-3-guanylhydrazone hydrochloride mitigates long-term cognitive impairment in a neonatal sepsis model with involvement of MAPK and NF $\kappa \mathrm{B}$ pathways
}

Luana Heimfarth, Alexandra Maria Santos Carvalho, Jullyana de Souza

Siqueira Quintans, Erik Willyame Menezes Pereira, Natália Teles Lima, Mikaella Tuanny Bezerra Carvalho, Rosana de Souza Siqueira Barreto, José Cláudio Fonseca Moreira, Edeildo F da Silva-Júnior, Martine Schmitt, et al.

\section{To cite this version:}

Luana Heimfarth, Alexandra Maria Santos Carvalho, Jullyana de Souza Siqueira Quintans, Erik Willyame Menezes Pereira, Natália Teles Lima, et al.. Indole-3-guanylhydrazone hydrochloride mitigates long-term cognitive impairment in a neonatal sepsis model with involvement of MAPK and NF $\kappa \mathrm{B}$ pathways. Neurochemistry International, 2020, 134, pp.104647. 10.1016/j.neuint.2019.104647 . hal02908631

\section{HAL Id: hal-02908631 \\ https://hal.science/hal-02908631}

Submitted on 31 Jul 2020

HAL is a multi-disciplinary open access archive for the deposit and dissemination of scientific research documents, whether they are published or not. The documents may come from teaching and research institutions in France or abroad, or from public or private research centers.
L'archive ouverte pluridisciplinaire HAL, est destinée au dépôt et à la diffusion de documents scientifiques de niveau recherche, publiés ou non, émanant des établissements d'enseignement et de recherche français ou étrangers, des laboratoires publics ou privés. 


\section{Indole-3-guanylhydrazone hydrochloride mitigates long-term cognitive impairment in a neonatal sepsis model with involvement of MAPK and NF $k B$ pathways}

The corrections made in this section will be reviewed and approved by journal production editor.

Luana Heimfarth Project administration Visualization Writing - review \& editing Writing - original draft Investigation Formal analysis Methodology Conceptualization ${ }^{\mathrm{a}, *}$ luahei@yahoo.com.br, Alexandra Maria Santos Carvalho Investigation Formal analysis Methodology a , Jullyana de Souza Siqueira Quintans Data curation Writing - original draft Validation Conceptualization a, Erik Willyame Menezes Pereira Investigation Formal analysis Methodology a , Natália Teles Lima Investigation Formal analysis Methodology a , Mikaella Tuanny Bezerra Carvalho Investigation Formal analysis Methodology a , Rosana de Souza Siqueira Barreto Writing - original draft Investigation Formal analysis Validation a , José Cláudio

Fonseca Moreira Writing - original draft Funding acquisition Project administration Supervision ${ }^{\mathrm{b}}$, Edeildo F. da Silva-Júnior Writing - original draft Investigation Resources ${ }^{c}$, Martine Schmitt Writing - original draft Project administration Supervision e , Jean-Jacques Bourguignon Writing - original draft Project administration Supervision e, Thiago M. de Aquino Writing - original draft Investigation Methodology

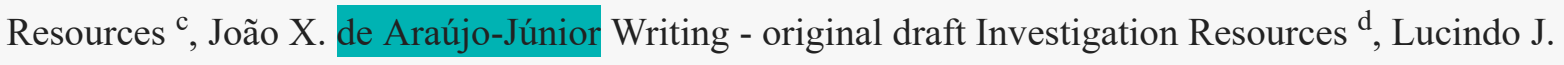
Quintans-Júnior Funding acquisition Project administration Supervision Resources Writing - review \& editing Writing - original draft Conceptualization ${ }^{\mathrm{a}, * *}$ lucindojr@gmail.com

aLaboratory of Neuroscience and Pharmacological Assay (LANEF), Graduate Program in Pharmaceutical Sciences, Federal University of Sergipe, São Cristóvão, Sergipe, Brazil

biochemistry Department, Federal University of Rio Grande do Sul, Porto Alegre, Rio Grande do Sul, Brazil

${ }^{\mathbf{c} C h e m i s t r y}$ and Biotechnology Institute, Federal University of Alagoas, Maceió, Alagoas, Brazil

dLaboratory of Medicinal Chemistry, Nursing and Pharmacy School, Federal University of Alagoas, Maceio, Alagoas, Brazil

'Département de Pharmacochimie Moléculaire, Centre de Neurochimie, Strasbourg University, Strasbourg, France 
* Corresponding author. Department of Physiology, Laboratory of Neuroscience and Pharmacological Assays (LANEF). Federal University of Sergipe, Av. Marechal Rondom, s/n, São Cristóvão, Sergipe, 49.100-000, Brazil.

${ }^{* *}$ Corresponding author.

\section{Abstract}

Background: Neonatal sepsis is defined as a systemic inflammatory response caused by a suspected or proven infection, occurring in the first month of life, and remains one of the main causes of morbidity and mortality in newborn and preterm infants. Frequently, survivors of neonatal sepsis have serious long-term cognitive impairment and adverse neurologic outcomes. There is currently no specific drug treatment for sepsis. Indole-3-guanylhydrazone hydrochloride (LQM01) is an aminoguanidine derivative that has been described as an anti-inflammatory, antihypertensive and antioxidant with potential applicability in inflammatory diseases.

Methods: We used a LPS-challenged neonatal sepsis rodent model to investigate the effect of LQM01 on cognitive impairment and anxiety-like behavior in sepsis mice survivors, and examined the possible molecular mechanisms involved.

Results: It was found that LQM01 exposure during the neonatal period reduces anxiety-like behavior and cognitive impairment caused by lipopolysaccharides (LPS) in adult life. Additionally, treatment with LQM01 decreased pro-inflammatory cytokine levels and reduced NFkB, COX-2, MAPK and microglia activation in hippocampus of neonatal mice. Furthermore, LQM01 was also able to prevent oxidative damage in hippocampus of neonatal mice and preserve brain barrier integrity.

Conclusions: LQM01 attenuated inflammatory reactions in an LPS-challenged neonatal sepsis mice model through the MAPK and NFkB signaling pathways and microglia activation suppression. All these findings are associated with mitigated cognitive impairment in 70 days-old LQM01 treated-mice.

General significance: We revealed the effect of LQM01 as an anti-septic agent, and the role of crucial molecular pathways in mitigating the potential damage caused by neonatal sepsis.

Keywords: Aminoguanidine; Guanylhydrazone; Cytokines; Microglia; Oxidative damage. endotoxemia

\section{Introduction}

Neonatal sepsis is a systemic inflammatory response caused by a suspected or proven infection, occurring in the first month of life (Raimondi et al., 2011). The etiology of this disease is unclear, and it has a range of degrees of inflammatory and metabolic responses (Bone et al., 1992). Neonatal sepsis remains one of the main causes of morbidity and mortality in newborn and preterm infants (Camacho-Gonzalez et al., 2013), and it is 
considered one of the major public health problems, especially in developing countries. Furthermore, it is responsible for about $42 \%$ of deaths in the first week of life, and around $13 \%$ of all lethality in neonates (Lawn et al., 2005; Liu et al., 2012). The neonatal phase possesses the highest lifetime risk of severe infections, with an estimated 400,000 newborn deaths every year (Liu et al., 2012).

The symptoms of neonatal sepsis are nonspecific and can be fever or hypothermia, hypotonia, respiratory distress, lethargy or irritability, feeding difficulties, seizures or abdominal distention. These systemic inflammatory responses affect several organs and can lead to multiple organ failure, or even death (Lohner et al., 2013; Mårtensson and Bellomo, 2015; Zarbock et al., 2014; Zea-Vera and Ochoa, 2015).

Researchers have demonstrated that neonatal sepsis directly provokes brain damages, such as white matter lesions and periventricular leukomalacia, and it is closely related to elevated rates of neonatal mortality ( Strunk et al., 2014). Moreover, survivors of neonatal sepsis frequently have serious long-term cognitive impairment and adverse neurologic outcomes (Adén et al., 2010; Hagberg et al., 2012; Lee et al., 2014). The development of long-term disabilities can affect the quality of life and daily activities in affected individuals.

The pathophysiology of brain dysfunction in sepsis is poorly undersood and has multifactorial characteristics. Acute brain damage, including blood-brain barrier (BBB) disruption, neural cell death, and white matter damage, has been described (Barichello et al., 2018; Polito et al., 2013). In addition, the neonatal immune system responses are different from adults in the way they interfere in sepsis progression. Increased production of reactive oxygen species (ROS) and pro-inflammatory cytokines, combined with the innately low levels of antioxidants defenses in neonates, have been implicated in the pathogenesis and complications of neonatal sepsis (Bajčetić et al., 2014; Machado et al., 2014; Zhang et al., 2018a). In neonates, the brain is immature and much more vulnerable to damage by poorly controlled and pervasive inflammation (Strunk et al., 2014). The susceptibility of the central nervous system (CNS) in neonates is related to a fragile innate immune response. Thus, changes in the CNS related to inflammation, oxidative damage and/or infection can persist in the longterm, causing suffering to the patients and being a challenge for current medicine (Dammann and Leviton, 1997).

There is currently no specific drug treatment for sepsis and those that are available are often ineffective, with pharmacoresistance being a major problem (Burnham et al., 2015). Several possible compounds to treat sepsis have been assessed in preclinical and clinical trials. Although some presented interesting preclinical results, they unfortunately failed in clinical trials (Fink and Warren, 2014). Thus, there is a lack of new agents that effectively treat neonatal sepsis. One group with potential are the inducible oxide nitric synthase (iNOS) inhibitors, such as aminoguanidine derivatives, which have already been shown to have potent antioxidant and anti-inflammatory properties (Natarajan et al., 2017; Sakthivel and Guruvayoorappan, 2016; Sandes et al., 2018).

Among these, one promising candidate is indole-3-guanylhydrazone hydrochloride (symbolically identified as LQM01), a new derivative obtained by a condensation reaction between indole-3-carboxaldehyde and aminoguanidine hydrochloride, as described by França et al. (2016) (Fig. 1). It presents an indole nucleus in the structure which appears to be the main pharmacological group of this aminoguanidine (Fujikawa et al., 1966; Prasad and McKay, 1967) (Fig. 1A). LQM01 has been shown to have outstanding anti-inflammatory 
and antioxidant properties in a mouse model, and may be able to play an important role in the effective treatment of inflammatory disease. (Sandes et al., 2018). Furthermore, other studies have reported that guanylhydrazone derivatives present retroviral (Amtmann et al., 2000), antifungal (Fujikawa et al., 1966) and antinociceptive properties (Sandes et al., 2018). LQM01 can produce a vasorelaxant and hypotensive profile by stimulating the release of $\mathrm{K}^{+}$through the $\mathrm{K}_{\mathrm{v}}$ ion channels and by partial blockade of voltage-dependent $\mathrm{Ca}^{2+}$ channels (Costa, 2017). In addition, an association with the serotonin pathway has also been reported for indole-guanylhydrazone derivatives (Buchheit et al., 1995).

\section{alt-text: Fig. 1}

\section{Fig. 1}
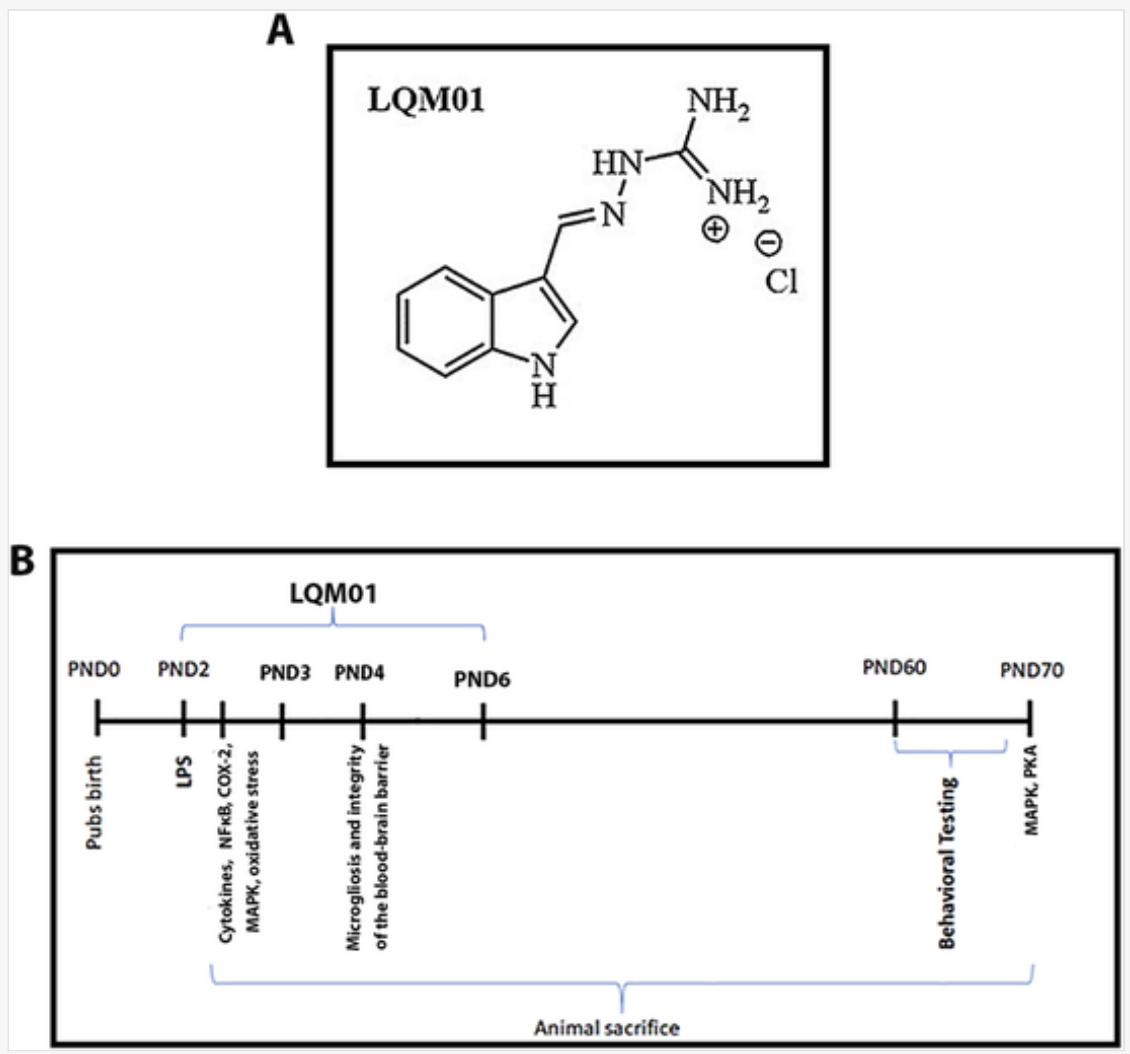

A) Indole-3-guanylhydrazone hydrochloride, adapted from (Sandes et al., 2018) B) Schematic representation of the early induction of neonatal sepsis. Offspring of both genders were randomly divided into three groups and treated with one injection of either saline solution or lipopolysaccharide (LPS) at PND2 to induce systemic inflammation. $1 \mathrm{~h}$ after the LPS administration the mice were treated with LQM01 (50 mg/kg, i.p.). Mice were sacrificed at $12 \mathrm{~h}$ (PND2), $48 \mathrm{~h}$ (PND4) and 70 days (PND70) after LPS injections. The behavioral assays were performed from PND60 to PND70. PND2, postnatal day 2; PND4, postnatal day 4; PND6, postnatal day 6; PND60, postnatal day 60; PND70, postnatal day 70.

The present study investigates the effect of LQM01 on neonatal sepsis in a rodent model and describes the probable molecular mechanisms involved in the improvement of cognitive impairment and anxiety-like behavior observed in sepsis survivors treated with this aminoguanidine derivative. Finally, we hypothesized that the LQM01 is able to reduce brain inflammation and oxidative neural damage in the early phase of neonatal sepsis, demonstrating a pivotal role in improvements in neurodevelopmental outcomes. 


\section{Methodology}

\subsection{Animals}

Male and female albino Swiss mice (3-months old, 28-32 g) were randomly housed ( $\mathrm{n}=6 /$ per group) in appropriate cages $\left(21 \pm 2{ }^{\circ} \mathrm{C}\right.$ ) with a $12 \mathrm{~h} \mathrm{light/dark} \mathrm{cycle} \mathrm{(light} \mathrm{from} 6$ to $18 \mathrm{~h}$ ), with free access to food (Purina $^{\circledR}$, Brazil) and water.

Male and female albino Swiss mice (2-21 days old) was housed with dams in appropriate cages $\left(21 \pm 2{ }^{\circ} \mathrm{C}\right)$ with a $12 \mathrm{~h} \mathrm{light/dark} \mathrm{cycle} \mathrm{(light} \mathrm{from} 6$ to $18 \mathrm{~h}$ ), with free access to food (Purina ${ }^{\circledR}$, Brazil) and water.

Experimental protocols were approved by the Animal Care and Use Committee at the Federal University of Sergipe at the Federal University of Sergipe and at Tiradentes University (CEPA/UFS: 62/15; CEUA/Unit: 011115). The ethical principles established by the Brazilian Society for Laboratory Animal Science (SBCAL) and by the National Institutes of Health (NIH) were respected. All tests were carried out by the same visual observer who was blinded to the experimental conditions. Additionally, a great effort was made to minimize the number of animals used, as well as the possible discomfort caused to them.

\subsection{Neonatal sepsis}

The day of birth was defined as PND0. For each experiment, offspring of both genders were randomly divided into two groups and were treated on postnatal day 2 (PND2) with a subcutaneous injection of $25 \mu \mathrm{g}$ lipopolysaccharides (LPS) preparation in saline (O26:B6 E. coli LPS; by Sigma Aldrich ${ }^{\circledR}$ ) or saline. After sepsis induction by LPS administration, the animals were returned to their cages to recover. They were fed by their mothers and stayed with them for 21 days. After this period, they were separated from their dams and kept in same sex groups (five animals per cage) until they were 60 days old (Comim et al., 2016).

\subsection{Experimental groups and schematic design of experiments}

Three independent experiments were performance for each analysis, using the offsprings of 3 different dams. The experimental unit is the single animal. For each experiment, three groups of newborn mice (Control, LPS and LQM01 $50 \mathrm{mg} / \mathrm{kg}$ ) aged 2 days old were used. Offspring of both genders were randomly divided into three groups:

Control group: one subcutaneous injection of saline solution at postnatal day 2 (PND2) and threated with

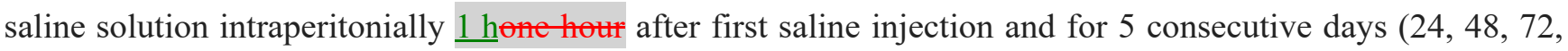
96, and 120 h) (Fig. 1B).

LPS group: one subcutaneous injection of lipopolysaccharide in saline (LPS) at postnatal day 2 (PND2) to induce systemic inflammation. Saline were administrated intraperitonially 1 hene hour after LPS administration and for 5 consecutive days (Fig. 1B).

LQM01 group: one subcutaneous injection of lipopolysaccharide in saline (LPS) at postnatal day 2 (PND2)

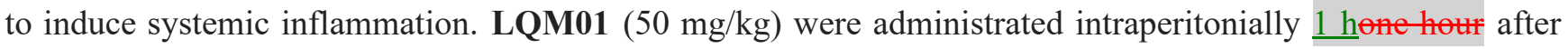
LPS administration and for 5 consecutive days (Fig. 1B). 
The molecular analyses were performed at $12 \mathrm{~h}$ (PND2) (inflammatory mediators and oxidative markers) and $48 \mathrm{~h}$ (PND4) (microglia activation and blood-brain barrier (BBB) permeability) after LPS administration.

The behavioral tests were done 60-65 days after LPS exposure (Fig. 1B). This timepoint was chosen based on (Comim et al., 2016).

\subsection{Behavioral testing}

Male mice from each group were randomly assigned to experimental subgroups $(\mathrm{n}=9-12)$. The locomotor activity, anxiety-related behavior learning, and memory tasks were performed at PND60-70. All tests were performed in the light phase of the day (between 9 a.m.m and 3 p.m.m, at a temperature of $25^{\circ} \mathrm{C}$ ). The training was performed randomly.

Open Field Test - The open field used consisted of a square arena $(40 \times 40 \mathrm{~cm})$, surrounded by $40 \mathrm{~cm}$ high white walls. The center area consisted of a square with the dimensions of $20 \times 20 \mathrm{~cm}$. Mice from each experimental condition were evaluated at PND60. The test began by placing a single mouse in the middle of the arena, and its activity was recorded for $5 \mathrm{~min}$. The field was carefully cleaned with $10 \%$ ethanol between each mouse. The parameters analyzed to evaluate locomotor activity in the open field were activity time (defined as the time that the animal remain in movement during the test) and time spent in central areas (both computed in seconds) scored manually. The number of crossing (center area entries), rearing intensity and grooming intensity were analyzed to assess environment exploration and anxiety-related behavior (Kawai et al., 2007). The parameters were scored manually.

Object Recognition Test - The test was performed as described in the literature by Pagnussat et al. (2015)( Pagnussat et al., 2015), with minor changes. This task evaluated nonspatial memory in rodents, quantifying object exploration and delimiting memory settings. Mice from each group were evaluated at PND62 and the exploration time of the objects was scored manually. Each mouse was allowed to explore the empty cage one day before the test for $10 \mathrm{~min}$. On the test day, each mouse was placed in a cage $(40 \times 40 \mathrm{~cm})$ with a black floor. The objects to be discriminated were cubes, pyramids, and cylinders, all made from different material and immovable when located in the field. Every test consisted of three trials. In the first trial ( $5 \mathrm{~min})$, there were two identical objects in opposite corners of the cage. The second trial was performed 180 min after the first trial and one new object replaced one of the old objects that had been previously shown, and the mouse was allowed to explore the object for $5 \mathrm{~min}$. The orders of presentation of the objects were counterbalanced to avoid bias. The third trial was performed $24 \mathrm{~h}$ after the second trial and one new object replaced one of the old objects that had been previously shown, and the mouse could explore the object for 5 min. The order of presentation of the objects were counterbalanced to avoid bias. Exploration was defined as directing the nose toward the object from a distance of $2 \mathrm{~cm}$ or closer or touching the object. The recognition index (RI) was used as a measure of the ability of the animal to distinguish new objects from familiar objects and reflected the exploration time that the animal explored the new object compared with the total exploration time.

$$
R I=\frac{\text { Exploration time of new object }(s)}{\text { Exploration time of old object }(s)+\text { Exploration time of new object }(s)}
$$




\subsection{Muscle strength (grip strength meter)}

68 days after LPS injection the muscle strength (grip strength meter) of the animals were tested. Hind paw and forepaw grip force were tested as previously described (Burnes et al., 2008; Meyer et al., 1979), through the Grip Strength Meter (Model EF 305, Insight Ltda., Ribeirão Preto, Brazil). The mice were placed on the grid of the apparatus and pulled by the tail to read the force of adhesion of the front legs. The animals were evaluated 3 times and the mean was calculated to obtain the absolute force $(\mathrm{g})$.

\subsection{Motor coordination}

68 days after LPS injection, the animals were evaluated motor coordination (Rota-rod, 4, 10, $20 \mathrm{rpm}$ ) ( Dunham and Miya, 1957; Quintans-Júnior et al., 2010). Possible motor deficits were evaluated through the rotarod apparatus which consisted of a rotating rod $4 \mathrm{~cm}$ in diameter. The animals were first placed on the rotating rod at a constant speed of 4, 10 and 20 RPM. The motor coordination was measure 3 times at 15, 30 and $45 \mathrm{~min}$.

\subsection{Molecular analysis}

Mice ( $\mathrm{n}=6-8)$. were killed by cervical dislocation either on PND2 (12 h after LPS administration) and the hippocampus were removed for molecular analysis. The molecular analysis was done in duplicate (Western blot and ELISA) or triplicate (protein determination, oxidative damage markers and evans blue spectroscopic assay). All data was obtained from three independents experiments.

\subsubsection{Preparation of total protein homogenate}

For Western blot assay the tissues were homogenized in $150 \mu \mathrm{L}$ of a RIPA lysis buffer consisting of $1 \mathrm{mM}$ EDTA, $20 \mathrm{mM}$ Tris-HCl (pH 7.5), $150 \mathrm{mM} \mathrm{NaCl}, 1 \mathrm{mM}$ EGTA, 1\% (w/v) sodium deoxicolate, 1\% (v/v) nonidet 40, containing proteases and phosphatases inhibitors. For electrophoresis analysis, samples were dissolved in a $25 \%(\mathrm{v} / \mathrm{v})$ solution containing $0.1 \%(\mathrm{w} / \mathrm{v})$ SDS. $40 \%$ glycerol, $5 \%$ mercaptoethanol, and $50 \mathrm{mM}$ Tris- $\mathrm{HCl}$ with a $\mathrm{pH}$ of 6.8 , and boiled for $5 \mathrm{~min}$.

For ELISA and oxidative stress assays, tissues were homogenized in $150 \mu \mathrm{L}$ of phosphate buffer solution (PBS) $50 \mathrm{mM}$ containing proteases and phosphatases inhibitors.

\subsubsection{Protein determination}

The protein concentration was determined by the method of Bradford (1976)(Bradford, 1976) using bovine serum albumin (BSA) as the standard.

\subsubsection{Determination of TNF- $\alpha$, IL-1 $\beta$, IL-6 and IL-10 levels in the hippocampus}

Tumor necrosis factor alpha (TNF- $\alpha$ ), Interleukin 1 beta (IL-1 $\beta$ ), Interleukin 10 (IL-10) and Interleukin 6 (IL6) levels were quantified in the supernatant of tissues by ELISA following the manufacturer's protocol (BDBioscience Pharmingen, San Diego, CA). 


\subsubsection{Western blot assay}

Tissue homogenates $(50 \mu \mathrm{g})$ and molecular weight marker (Biorad, Precision Plus Protein ${ }^{\mathrm{TM}}$ Prestained Standard) were separated by SDS-PAGE and transferred to PVDF membranes (BioRad) for $16 \mathrm{~h}$ at $25 \mathrm{~V}$ in a transfer buffer (48 Mm Tris, $39 \mathrm{mM}$ glycine, 20\% methanol). The PVDF membranes were washed for $15 \mathrm{~min}$ in Tris-buffered saline with 0.1\% Tween-20 (T-TBS; $0.5 \mathrm{M} \mathrm{NaCl}, 20 \mathrm{Mm}$ Tris, 0.1\% Tween-20, pH 7.5), followed by $1 \mathrm{~h}$ incubation in blocking solution (T-TBS plus 5\% defatted dried milk). After incubation, the blots were washed three times for 15 min with T-TBS, and then incubated overnight at $4{ }^{\circ} \mathrm{C}$ in blocking solution containing the following antibodies: anti-phospho-JNK (clone 81E1, cs 4668); anti-JNK (cs 9252); anti-phospho-p38MAPK (Thr180/Tyr182) (clone D3F9, cs 4511) anti-p38MAPK (clone D13E1, cs 8690), anti-ERK1/2 (clone 137F5, cs 4695), anti-phospho ERK1/2 (Thr202/Tyr204) (cs 9101), anti-PKAc $\alpha$ (clone D38C6, cs 5842), anti-NFkB (clone D14E12, cs 8242), anti-phospho NFkB (Ser 536) (clone 93H1, cs 3033), anti-COX-2 (cs 4842) and anti- $\beta$-actin (clone D6A8, cs 8457) diluted 1:1000. The blots were then washed three times for $15 \mathrm{~min}$ with T-TBS and incubated for $2 \mathrm{~h}$ in blocking solution containing peroxidase conjugated anti-rabbit IgG diluted 1:2000. The blots were washed twice again for 15 min with T-TBS and twice for $15 \mathrm{~min}$ with TBS. The blots were then developed using a chemiluminescence substrate. Blots were quantified, and optical density values were obtained for the studied proteins. All results were expressed as a relative ratio to $\beta$-actin.

\subsubsection{Immunofluorescence}

Mice were killed by cervical dislocation on PND4 (48 $\mathrm{h}$ after LPS exposure). The brain was removed, fixed in $4 \%$ paraformaldehyde in $0.1 \mathrm{M}$ phosphate buffered saline (PBS), $\mathrm{pH} 7.4$ for $24 \mathrm{~h}$ and cryoprotected by immersing in a $15 \%$ and then a $30 \%$ sucrose solution in PBS at $4{ }^{\circ} \mathrm{C}$. Serial coronal sections $(30 \mu \mathrm{m})$ of the hippocampus were obtained using a cryostat at $-20{ }^{\circ} \mathrm{C}$ (Leica). Some sections were processed for immunofluorescence using ionized calcium binding adaptor molecule 1 (IBA1) antibody. The free-floating sections were preincubated in $2 \%$ bovine serum albumin (BSA) diluted in PBS, containing 0.3\% Triton X-100 (PBS-Triton X-100 0.3\%) for 30 min. Immunofluorescence for IBA1 was carried out after two days of incubation at $4{ }^{\circ} \mathrm{C}$ with the following antibody: rabbit polyclonal anti-IBA1 (Wako Chemicals USA, catalog number 019-19741) diluted 1:1000 in BSA 1\% and/PBS-Triton X-100 0.3\%. The negative controls were performed omitting the primary antibodies. After several washes in PBS, tissue sections were incubated with anti-rabbit Alexa 488 diluted 1:1000 in PBS-Triton X-100 0.3\% for $2 \mathrm{~h}$ at room temperature. After several washes in PBS, tissue sections were incubated with DAPI (Roche) (1:2000) for $15 \mathrm{~min}$. The sections were then washed in PBS and transferred to gelatinized slides, mounted with glycerol-DABCO, covered with coverslips and sealed with nail polish. The images were obtained with an Olympus microscope and then 10 photomicrographs of each animal for IBA-1 and DAPI were analyzed with an Image J.

\subsubsection{Oxidative damage markers}

The formation of thiobarbituric acid reactive substance (TBARS) was quantified as an index of lipid peroxidation as previously described (Draper and Hadley, 1990). Briefly, the samples were mixed with trichloroacetic acid 10\% (TCA) and $0.67 \%$ thiobarbituric acid and heated at $100{ }^{\circ} \mathrm{C}$ for $30 \mathrm{~min}$. TBARS were determined at $532 \mathrm{~nm}$ in a spectrophotometer reader. Results are expressed as nmol MDA/mg of protein. In 
order to measure the levels of reduced thiol (-SH) groups in protein and nonprotein fractions from animal tissues, 80 ??g of the sample was reacted with $10 \mathrm{mM}$ of 5,5-dithionitrobis2-nitrobenzoic acid. After $30 \mathrm{~min}$ incubation at room temperature, the absorbance was read in a spectrophotometer set at $412 \mathrm{~nm}$ (Ellman, 1959). Results are expressed as $\mu \mathrm{mol} \mathrm{SH} / \mathrm{mg}$ protein.

\subsection{Evans blue spectroscopic assay}

The assessment of blood-brain barrier (BBB) permeability was adapted from (Nadeau et al., 2018; Zou et al., 2018). $48 \mathrm{~h}$ after LPS administration, the Evans blue (EB) was injected (3\%, i.p.) and the dye circulated for $2 \mathrm{~h}$. The brain was then excised, cleaned, weighed, and homogenized in PBS. The optical density of the supernatant was estimated at $625 \mathrm{~nm}$ by a microplate reader. A standard curve for the EB was obtained.

\subsection{Statistical analysis}

The results were expressed as a mean \pm S.E.M of three independents experiments. Samples were assessed for normal distribution by the Shapiro-Wilk's test. Differences between multiple groups were analyzed using oneway or two-way analyses of variance (ANOVA) followed by Tukey's test or Bonferroni test, respectively. Differences were considered significant if $p<0.05$. The statistical analyses were assessed using the GraphPad Prism $^{\circledR} 5.0$ software (GraphPad Prism Software Inc., San Diego, CA, USA).

\section{Results}

Initially, we addressed the question of whether LQM01 (50 mg/kg i.p.) was able to improve the adverse neurologic outcomes of neonatal sepsis in LPS-challenged mice. Fig. 2 represents the effects of neonatal exposure to LPS in LQM01 treated or untreated mice in respect of locomotion, exploration and anxiety likebehavior at PND 60. The open field task was used to evaluate autonomous behavior, focusing on the locomotor and emotional activity of mice. The locomotor activity is assessed by the following parameters: active time and grooming behavioral. The anxiety-like behavior can be observed by the following parameters: number of entries and time spent on the central area, latency time in the central area, number of rearing and amount of fecal boli.

alt-text: Fig. 2

\section{Fig. 2}


A

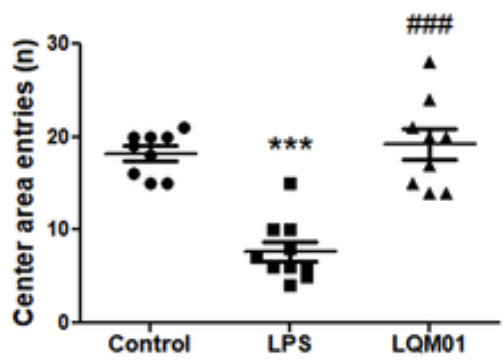

C

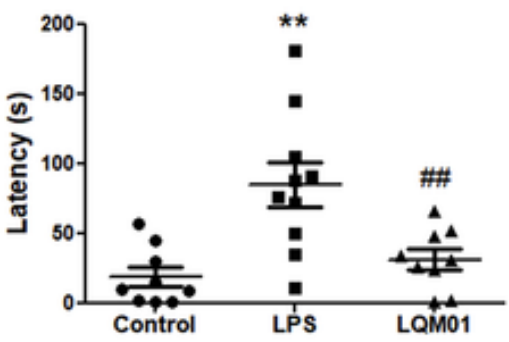

E

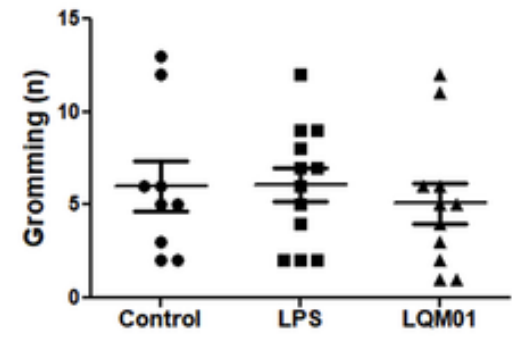

G

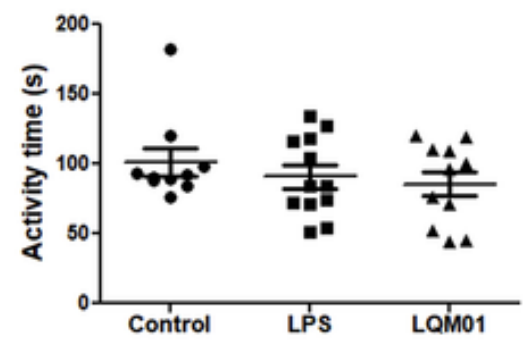

B

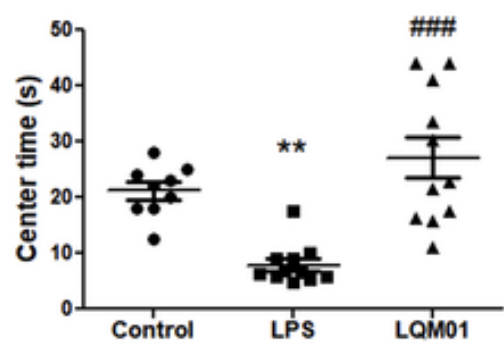

D

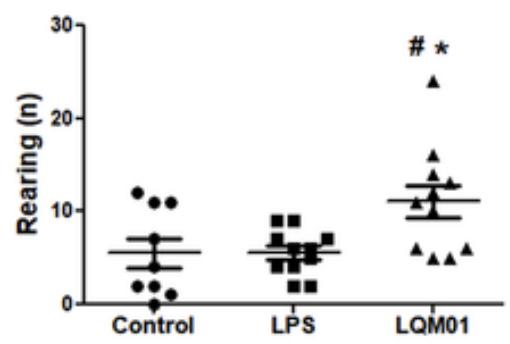

F

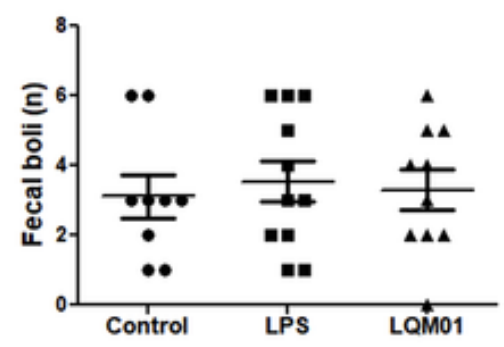

H

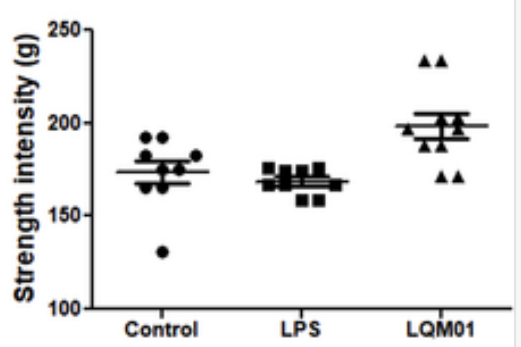

I

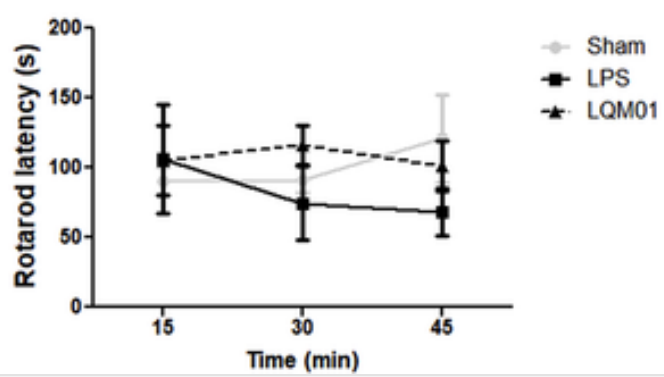

Effect of LQM01 (50 mg/kg i.p.) on lipopolysaccharide (LPS)-induced alterations in parameters observed in the open field test and Grip strength meter 60 days after LPS exposure. Each animal freely explored the open field test apparatus for 5 min and the number of entrances into the central area (A), total time spent in the central area (B), central area latency (C), frequency of rearing (D), frequency of grooming (E), number of fecal boli (F), activity time (G), muscle strength (H) and time in rotarod apparatus (I) were collected and recorded. Results are expressed as the mean \pm SEM of three independent experiments. Statistically significant differences between the control group and LPS group was determined by one-way ANOVA followed by Tukey's post hoc test: ${ }^{*} p<0.05, * * \mathrm{p}<0.01$ vs control mice; \#p $<0.05, \# \# \mathrm{p}<0.01$, \#\#\# $<0.001$ vs LPS group. 
The animals assessed in the open field test showed no differences in active time, grooming behavior or total of fecal boli (Fig. 2 E, F, G). However, we demonstrated a decreased number of entries $(p<0.001)$ to and time spent $(\mathrm{p}<0.001)$ in the central area in the untreated LPS group (Fig. 2B, D) and increased latency time $(\mathrm{p}<0.01)$ in crossing the central line (Fig. 2C). The administration of LQM01 in the neonatal period was able to significantly $(\mathrm{p}<0.01 ; \mathrm{p}<0.001)$ prevent these events and diminish the anxiety-like behavior induced in the LPS-challenged neonatal sepsis mice model (Fig. 2A, B, and C). In addition, the open field results showed an increased frequency of rearing $(\mathrm{p}<0.05)$ (Fig. 2E) in the LQM01 treated mice, corroborating its anxiolytic profile. No alterations were observed in muscule strength and motor coordination when assessed by a grip strength meter and rotarod assays, respectively (Fig. 2H and I).

Next, we study whether LQM01 was able to reduce the cognitive deficit caused by LPS exposure in neonatal phase. Fig. 3 represents the effect of LQM01 treatment (50 mg/kg i.p.) during PND2 to PND6 on short-term memory $(3 \mathrm{~h})$ and long-term memory $(24 \mathrm{~h})$ at PND64-65. The results showed that LPS disrupted both the short and long-term memory performance of the mice, decreasing the recognition index $(p<0.001)$ (Fig. 3 $\mathrm{D}, \mathrm{F})$ and no differences in the exploratory frequency time was observed between the old and new object $(\mathrm{p}>0.05)$ (Fig. 3C, E). However, LQM01-treated mice spent more time examining the new object (3 h: $\mathrm{p}<0,01 ; 24 \mathrm{~h}: \mathrm{p}<0,01)$, similar to control-group, and the recognition index exploratory frequency between old and new object in the LQM01-treated group also was similar to control (saline) group (3 and $24 \mathrm{~h}$ : p < 0.001) (Fig. 3). These results showed that LQM01 prevents the memory impairment caused by neonatal inflammation induced by LPS.

alt-text: Fig. 3 
A

Habituation

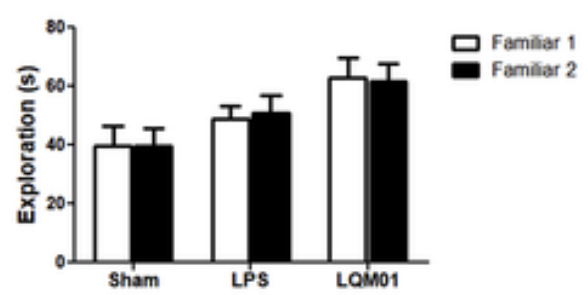

C

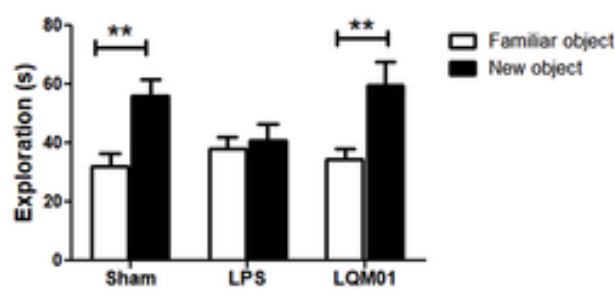

$\mathbf{E}$

24 hours
B

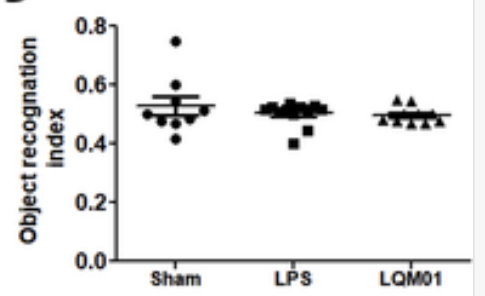

D

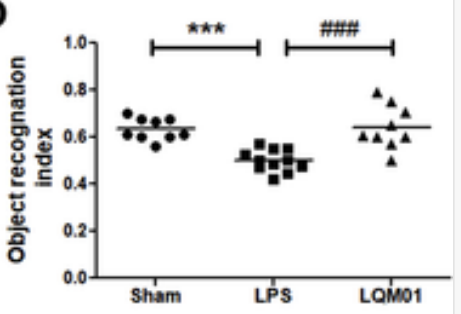

$\mathbf{F}$

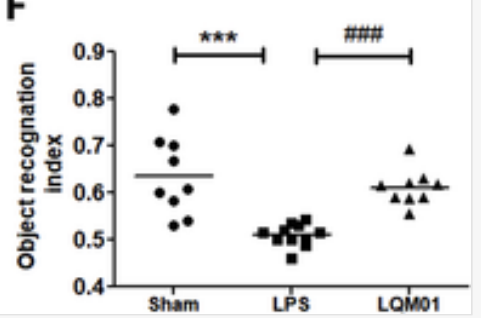

Effects of LQM01 (50 mg/kg i.p.) on cognitive function assessed using the novel object recognition test in surviving mice at habituation time (time 0) (A, B), after $3 \mathrm{~h}$ (short-term memory) (C,D) and after $24 \mathrm{~h}$ (long-term memory) (E,F). Each mouse was placed in a cage $(40 \times 40 \times 40 \mathrm{~cm})$ with a black floor. The objects used were cubes, pyramids, and cylinders, all made from different materials and immovable when located in the field. Results are expressed as the mean \pm SEM of three independent experiments. Statistically significant differences between the control group and LPS group was determined by one-way ANOVA following by Tukey's post hoc test: ${ }^{* *} p<0.001 v s$ control mice; \#\#\# $<0.001 v s$ LPS group.

We then analyzed some important signaling pathways involved with motor coordination, cognitive behavior and memory in 70-day-old mice. The results showed that LPS caused an increase in phosphoJNK/totalJNK ratios $(\mathrm{p}<0.01)$ and phosphop38MAPK/totalp38MAPK ratios $(\mathrm{p}<0.01)$ in the LPS group, compatible with activation of these kinase activities. In LQM01 group no change was observed in phosphoJNK/totalJNK ratios and phosphop38MAPK/totalp38MAPK ratios, being similar to control group (Fig. 4A and B). In addition, Western blot analysis of phospho-ERK1/2/total ERK 1/2 levels and PKAc $\alpha$ immunocontent showed unaltered levels of these markers in the hippocampus of 70 days-old mice (Fig. 4C and D).

alt-text: Fig. 4

\section{Fig. 4}


A

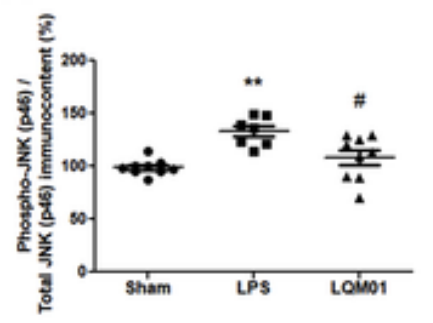

PND 70

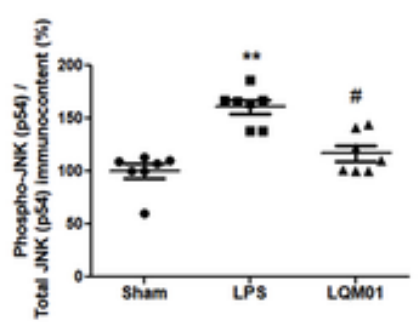

B

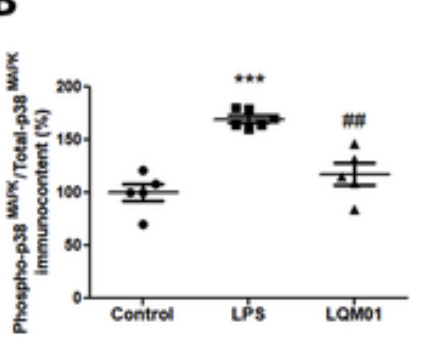

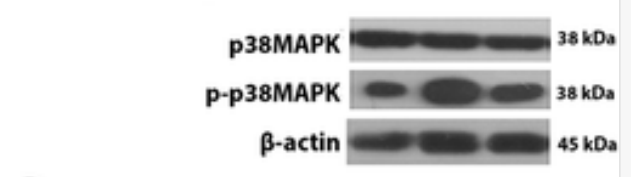

C

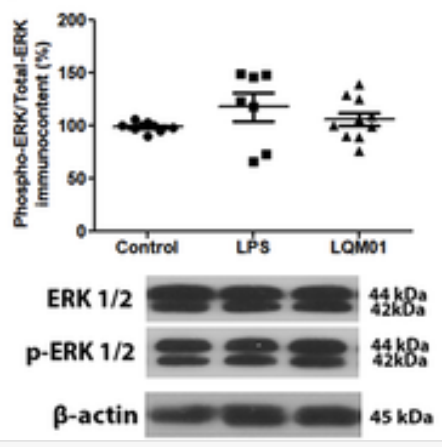

D

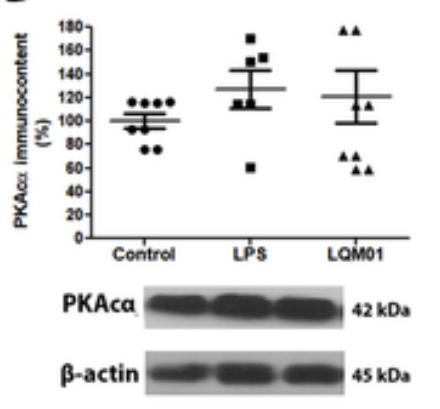

Effects of LQM01 (50 mg/kg i.p.) on SAP/JNK, p38MAPK, ERK1/2 and PKAc $\alpha$ levels in the hippocampus of 70-day-old pups. Western blot assay with anti-total and anti-phosphorylated SAP/JNK antibodies (A); anti-total and anti-phosphorylated p38MAPK antibodies (B); anti-total and anti-phosphorylated ERK1/2 antibodies (C) and anti- PKAc $\alpha$ antibodies (D). Representative blots are shown. Data are reported as mean \pm SEM of three independent experiments and expressed as percent of control. All experiments were done in duplicate. Statistically significant differences between control group and LPS group determined by oneway ANOVA followed by Tukey's post hoc test: ${ }^{* *} p<0.01$ vs control mice; $\# \mathrm{p}<0.05$ vs LPS group.

In an attempt to search for the effect of LQM01 exposure during the septic period we performed several experiments 12 after LPS administration in hippocampus of neonatal mice (PND2). This timepoints represents the peaks of inflammatory process in brain of neonatal mice exposure to LPS. In septic events occurs an increase of inflammatory mediators (TNF- $\alpha$, IL-1 $\beta$ and IL-6), activation of several inflammatory pathways (NFkB, COX-2 and MAPK cascades) in the first $12 \mathrm{~h}$ after LPS administration, returning to basal levels after 24-48 h. This neuroinflammation observed in $12 \mathrm{~h}$ after LPS exposure could cause glial activation, oxidative damage and neuroplastic changes that are associated to the neurological behavior impairment observed in adult life. So, we addressed to determine the effect of LQM01 in inflammatory response caused by LPS in septic period represent by PND2.

The central anti-inflammatory profile of LQM01 (50 mg/kg i.p.) is shown in Fig. 5. The average levels of hippocampal TNF- $\alpha(\mathrm{p}<0.01)$, IL-1 $\beta(\mathrm{p}<0.001)$ and IL-6 $(\mathrm{p}<0.01)$ in the LPS-treated control groups were significantly higher than those in the non-LPS saline-treated control groups. LQM01 was able to significantly decrease TNF $\alpha(p<0.01)$, IL1 $\beta(p<0.05)$ and IL-6 $(p<0.05)$ levels in the hippocampus of neonatal pups $12 \mathrm{~h}$ after LPS injection compared to the LPS-challenged control group. No alteration was observed in the IL10 production in the hippocampus of 2 days old mice (Figure A,B,C,D). 
A

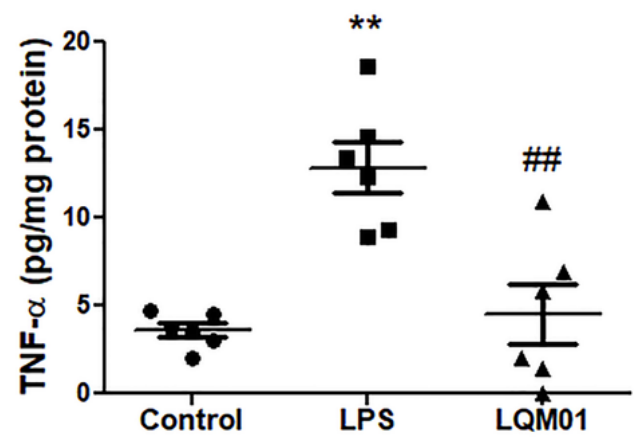

B

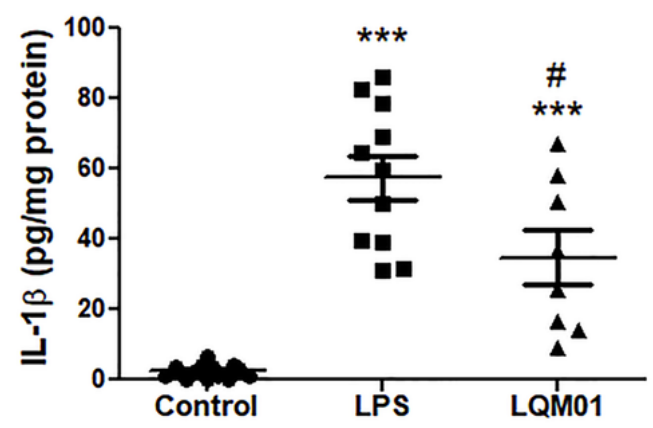

C

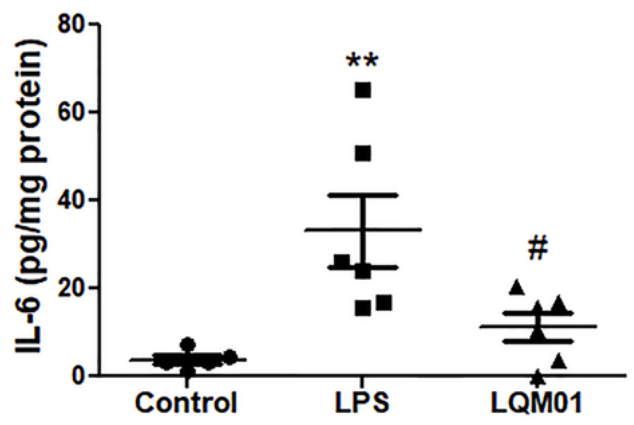

D

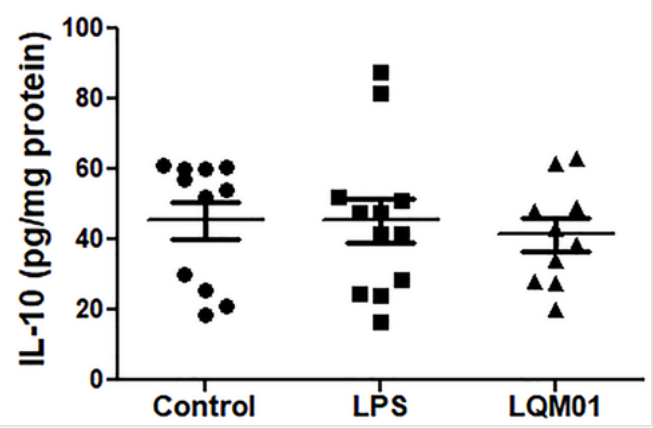

Effects of LQM01 (50 mg/kg i.p.) on TNFa levels (A), IL1 $\beta$ (B), IL-6 (C) and IL-10 (D) levels in hippocampus 12 h after induction. Results are expressed as the mean \pm SEM of three independent experiments and expressed in percentage of control. All experiments were done in duplicate. Statistically significant differences were determined by one-way ANOVA followed by Tukey's post hoc test: **p $<0.01 * * * p<0.001$ vs control mice; $\# \mathrm{p}<0.01$, \#\#p $<0.01$, \#\#\# $<0.001$ vs LPS group. 
Fig. 6 summarizes the effect of LQM01 (50 mg/kg i.p.) on NFkB and COX-2 activation in the hippocampus of neonatal mice $12 \mathrm{~h}$ after LPS injection. We demonstrated that the LPS increased phospho-NFkB (Ser536)/total NFKB immunocontent ratios $(\mathrm{p}<0.01)$ and COX-2 immunocontent $(\mathrm{p}<0.05)$ compared to the untreated control group. The group treated with LQM01 presented unaltered phospho-NFkB (Ser536)/total $\mathrm{NF} \kappa \mathrm{B}$ immunocontent ratios and COX-2 immunocontent compared to control group (Fig. 6A and B).

alt-text: Fig. 6

Fig. 6

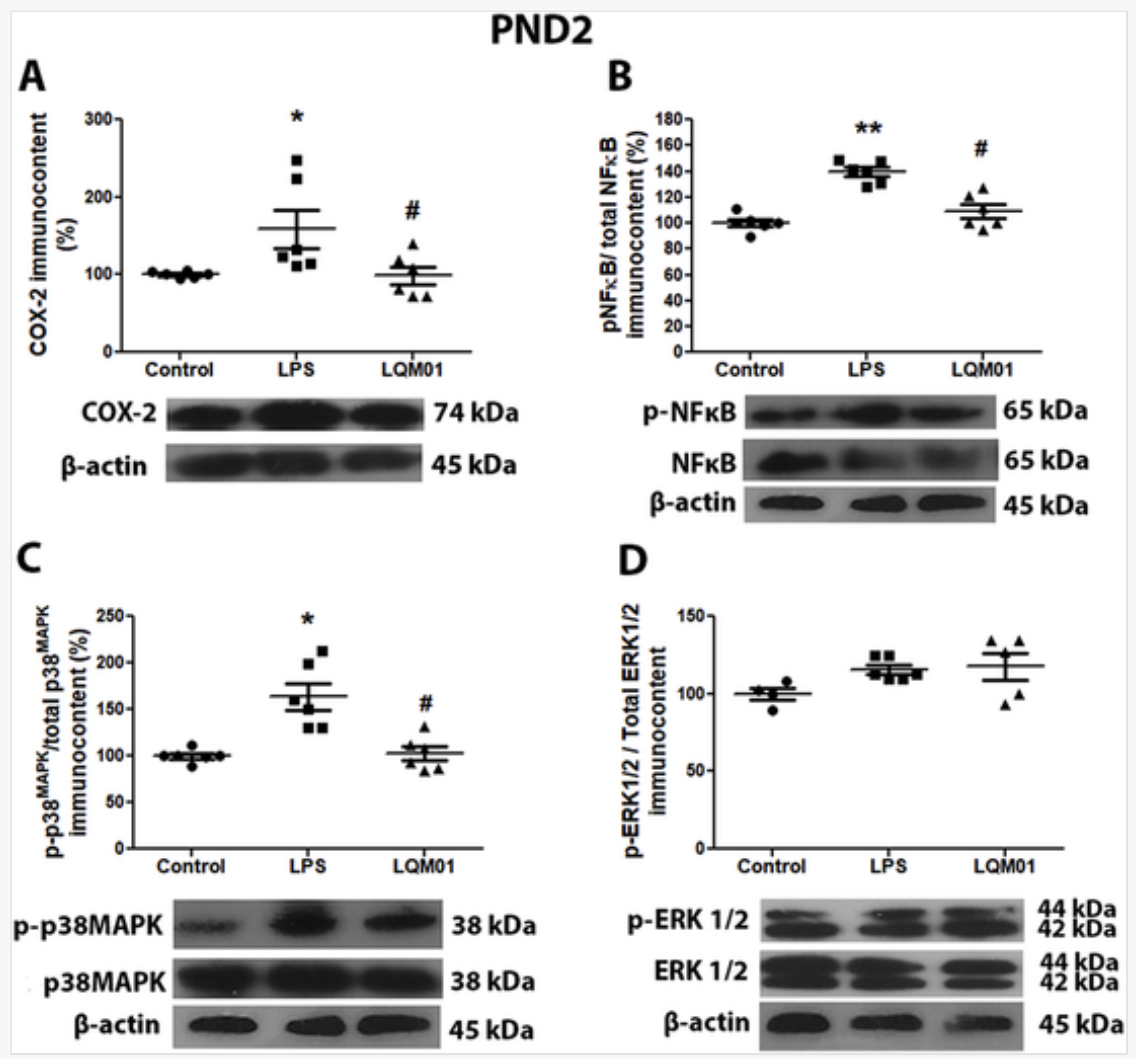

Effects of LQM01 (50 mg/kg i.p.) on COX-2, NF $\kappa$ B, p38 MAPK and ERK1/2 $12 \mathrm{~h}$ after LPS injection on postnatal day 2 (PND2). Western blot assay with anti-COX-2 antibodies (A); anti-total and anti-phosphorylated NFxB antibodies (B); anti-total and anti-phosphorylated p38MAPK antibodies (C) and anti-total and anti-phosphorylated ERK1/2 antibodies (D). Representative blots are shown. Data are reported as means \pm SEM of three independent experiments and expressed as percent of control 6 animals. All experiments were done in duplicate. Statistically significant differences between control group and LPS group determined by one-way ANOVA followed by Tukey's post hoc test: ${ }^{*} p<0.05, * * p<0.01$ vs control mice; \#p $<0.05$ vs LPS group.

Fig. 6 also represents the effect of LQM01 (50 mg/kg i.p.) on the regulation of the MAPK pathway in the hippocampus of neonatal pups at septic period. p38MAPK and ERK1/2 immunocontent were assessed by Western blot. The results determined that LQM01 was able to significantly reduce phospho-p38 $8^{\mathrm{MAPK}} / \mathrm{total}$ $\mathrm{p} 38^{\mathrm{MAPK}}$ immunocontent ratio $(\mathrm{p}<0.05)$ compared to the untreated LPS group in the hippocampus of mice $12 \mathrm{~h}$ after LPS exposure. However, no significant difference was demonstrated in phospho-ERK1/2/total ERK1/2 immunocontent ratio at $12 \mathrm{~h}$ after LPS-sepsis induction ( $p>0.05)$ (Fig. $6 \mathrm{C}, \mathrm{D})$. Data clearly showed 
that the LQM01 administration prevented inflammatory pathway cascade activation caused by LPS (Fig. 6A, $\mathrm{B}$ and $\mathrm{C})$.

The modulation in inflammatory mediators suggested that microglia might be involved in the response LPS challenge (Cardoso et al., 2015a) and the microglia reactivity is enhanced $48 \mathrm{~h}$ after LPS injection. The role of glial cells in the LQM01 mechanism of action is represented in Fig. 7. LQM01 treatment induced an inhibitory effect on the microglia activation induced by LPS $48 \mathrm{~h}$ after LPS exposure in the hippocampus. In the untreated LPS group increased IBA-1 immunoreactivity and enhanced microglial cell body size were observed. However, in the hippocampus of LQM01 treated mice the results showed lower IBA-1 immunostaining cells and diminished microglia body size (Fig. 7A and B).

alt-text: Fig. 7

Fig. 7

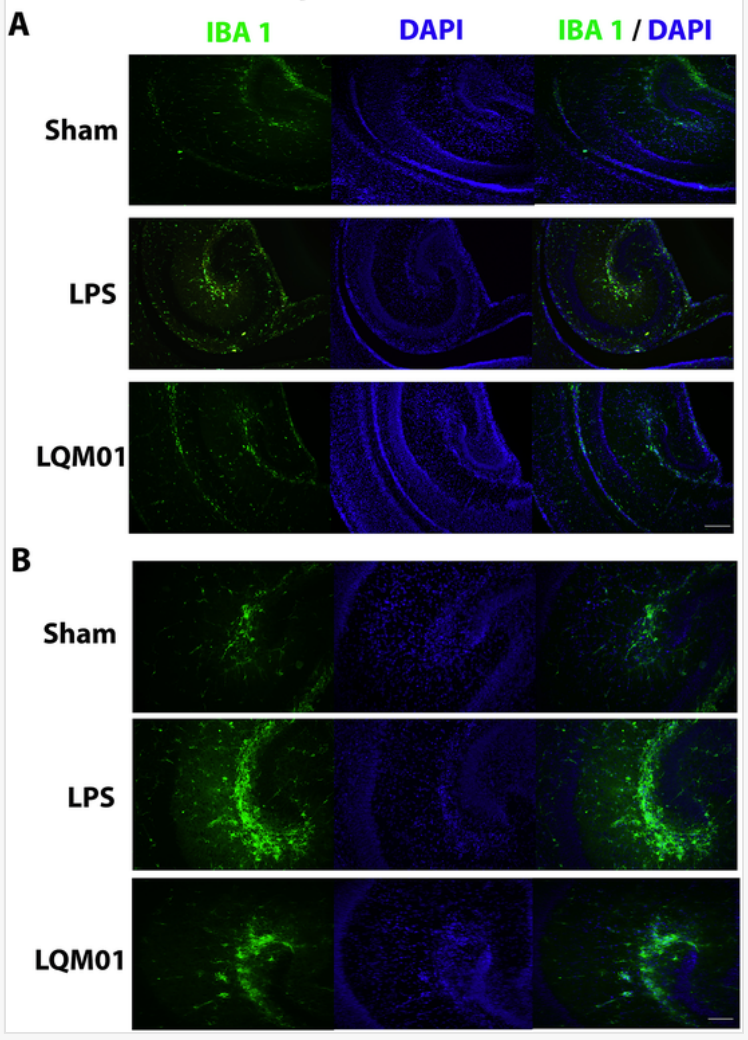

Effects of LQM01 (50 mg/kg i.p.) on IBA1 levels in hippocampus of mice at postnatal day 4 (PND4). Immunohistochemistry for IBA1 (green) and DAPI stained (blue). The panels were obtained by optical microscopy. Representative images of 6 animals. Bar scale $=60 \mathrm{~mm}$ (magnification: 10) (A); $30 \mathrm{~mm}$ (magnification: 20) (B). (For interpretation of the references to colour in this figure legend, the reader is referred to the Web version of this article.)

In an attempt to evaluate the role of LQM01 treatment on oxidative damage in hippocampus of septic mice, the levels of TBARS and protein oxidation were measured. The results showed that LQM01 was able to significantly decrease the lipoperoxidation in hippocampus $(\mathrm{p}<0.05)$ of mice (Fig. 8A). No alteration was observed in protein oxidation between LQM01 -treated LPS mice and untreated LPS mice (Fig. 8B). 
alt-text: Fig. 8

\section{Fig. 8}

A

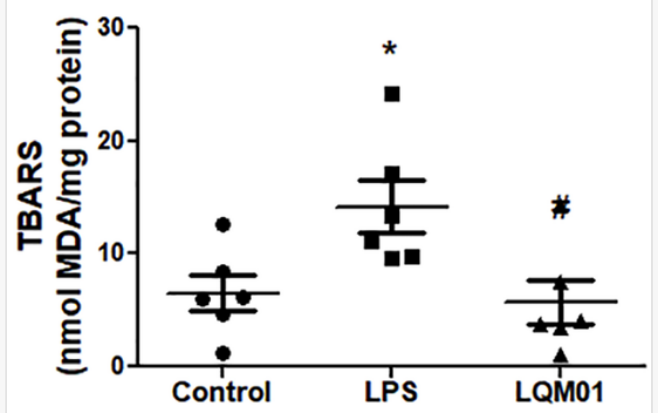

B

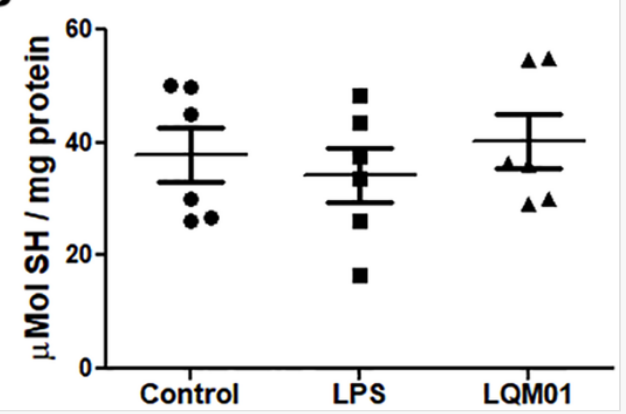

Effect of LQM01 (50 mg/kg i.p.) on parameters of oxidative imbalance in hippocampus of neonatal mice. Thiobarbituric acid reactive substance (TBARS) (A); Total reduced thiol content (SH) (B). Data are reported as mean \pm SEM of three independent experiments and expressed in percentage of control. All experiments were done in triplicate. Statistically significant differences from control group or LPS group, as determined by one-way ANOVA following by Tukey's post hoc test: * $p<0.05 v s$ control mice; $\# \mathrm{p}<0.05$ vs LPS group.

Finally, the integrity of the blood-brain barrier (BBB) was investigated using Evans blue dye extravasation $48 \mathrm{~h}$ after the LPS administration (PND4). The neonatal sepsis caused a disruption in the integrity of BBB, provoking higher barrier permeability in the untreated LPS-group compared to the saline-treated group $(\mathrm{p}<0.05)$. The administration of LQM01 (50 mg/kg i.p.) enhanced BBB integrity $(\mathrm{p}<0.05)$, diminishing the EB dye extravasation (Fig. 9).

alt-text: Fig. 9

\section{Fig. 9}

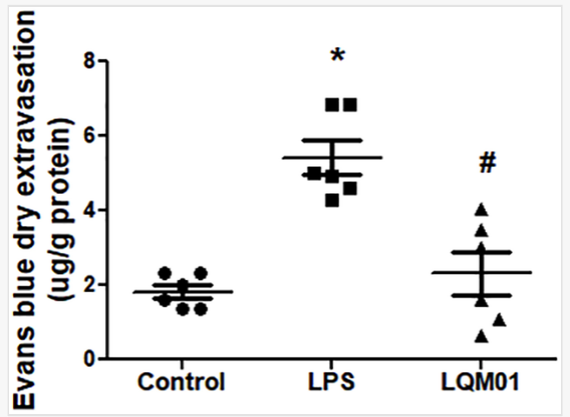


Effect of LQM01 (50 mg/kg i.p.) on blood brain barrier (BBB) permeability. Data are reported as mean \pm SEM of three independent experiments and expressed in percentage of control. All experiments were done in triplicate. Statistically significant differences between control group and LPS group determined by one-way ANOVA followed by Tukey's post hoc test: $* p<0.05$ vs control mice; $\# \mathrm{p}<0.05$ vs LPS group.

\section{Discussion}

Neonatal sepsis is a complex clinical condition that is difficult to treat and remains a challenge for modern medicine ${ }^{1}$. The use of new chemical entities (NCE) or drug repositioning have been options that often arise in clinical therapy, but the levels of clinical efficacy and their effect on patient life expectancy are still discouraging (Burnham et al., 2015). Thus, new drugs are urgently needed, and many researchers are looking for compounds to treat sepsis, especially in neonatal patients, in whom the disease can result in permanent damage or even death (Goldenberg et al., 2011). It has been suggested that some aminoguanidine compounds, because of their known potent antioxidant and anti-inflammatory properties, may have beneficial effects for sepsis patients and be able to mitigate symptoms and CNS damage (Alden et al., 1998; Soliman, 2014). In this study we attempted to investigate the possible beneficial effects of LQM01 in the treatment of impaired behavioral responses, cognitive deficit and anxiety-like behavior caused by neonatal sepsis, as well as the molecular mechanisms of any actions.

Neonatal sepsis is a major cause of morbidity and mortality in neonatal intensive care units; however, the mortality rate has been decreasing over recent years, highlighting the long-term sequelae caused by this type of systemic inflammation. It is known that sepsis has neurodevelopmental outcomes caused by inflammatory injury (Bakhuizen et al., 2014). Moreover, Commin et al.(Comim et al., 2016) reported that LPS exposure during the neonatal period causes cognitive impairment, depression, and anxiety in mice adult life. So, the neuroinflammation that occurs in neonatal phase provoke a neurological damage that are related to adult behavioral impairment observed during the adult life.

Early treatment with antibiotics decreases sepsis mortality and morbidity; however, the severe complications caused by neonatal sepsis, such as brain damage, neurodevelopmental delay, and cognitive impairment remain a serious life-threatening condition. There is, therefore, a great need for agents that effectively treat the longterm sequelae of neonatal sepsis. A good strategy is to decrease the neuroinflammation and the oxidative damage caused during the septic period, neonatal phase, This work describes the main actions of LQM01 $(50 \mathrm{mg} / \mathrm{kg}$ of body weight) in neurodevelopmental outcomes, showing some molecular targets for LQM01. Ours results show that the reduction in inflammatory and oxidative stress provoked by LQM01 in the first $24 \mathrm{~h}$ after LPS administration could be associated to the improvement of cognitive impairment in adult live. The results support the efficacy of LQM01 as a possible anti-septic agent due to its high capacity to attenuate inflammatory and oxidative damage.

Initially, we described the effect of LQM01 treatment during the critical septic period on the neurodevelopmental disruption caused by an inflammatory brain process. The open field task was used to evaluate autonomous behavior, focusing on the locomotor and emotional activity of mice, as indicators of CNS neurodevelopment integrity. The results demonstrated that LQM01 exposure during the neonatal period 
reduced anxiety-like behavior of developing mice, indicated by an increased number of entries and time spent in the central area, enhanced the number of rearing and decreased central area latency time. The frequency of rearing is commonly used as a measure of exploration and anxiety. A high frequency of this behavior indicates increased exploration and/or a lower level of anxiety (Ge et al., 2015). The number of central area entries and the time spent in the central area are measures of exploratory behavior and anxiety. A high frequency/duration of these behaviors indicates high exploratory activity and low anxiety (Prut and Belzung, 2003). Thus, the results strongly suggested that LQM01 has a protective effect on the CNS during this phase. Study has been described the anti-anxiety activity of an aminoguanidine compounds, similar to LQM01 (Gilhotra and Dhingra, 2009), corroborating our results.

Memory performance was evaluated using the novel object recognition task. This task evaluates nonspatial memory in rodents, quantifying the exploration of objects, and measuring memory (Antonio et al., 2016; Ennaceur and Delacour, 1988). Our results indicated a deficit of both short and long-term memory in LPSexposed mice pups, corroborating the work of (Comim et al., 2016). However, LQM01 treatment was able to improve this memory deficit, restoring the levels to those of the control group, and demonstrating the protective activity of this compound. The anti-inflammatory profile of LQM01 demonstrated by our group ( Sandes et al., 2018) can contribute to the prevention of long-term cognitive impairment since brain inflammation is the main step in the development of this neurological deficit. Moreover, our results are in agree with Li et al. (2017) that show that an aminoguanidine compound could alleviate a cognitive impairment via downregulated inflammatory and oxidative process.

It has been demonstrated that complex molecular mechanisms are implicated in behavioral impairment of sepsis (Bersani et al., 2015; Cardoso et al., 2015b). In this regard, we analyzed the MAPK family, an important signaling cascade that has been associated with anxiety like-behavior and memory acquisition, when the animals were 70 days-old (Wefers et al., 2012; Zhang et al., 2018b). MAPK cascade mediates signals initiated by a variety of physiological and pathological factors, being an important factor in the progression of several diseases (Li et al., 2018), including cognitive deficit and memory loss (Wefers et al., 2012; Zhang et al., 2018b ) .

Our results showed that LPS-treated mice present a misregulated MAPK cascade in adult life, contributing to the declined cognitive deficit and increased anxiety like-behavior of LPS mice. These findings could mean disrupted cellular homeostasis of neuronal cells since MAPK phosphorylation/dephosphorylation plays critical roles in brain function, modulating protein-mediated processes related to the proliferation, differentiation, and functioning of neurons (Corrêa and Eales, 2012; Peng et al., 2018; Zeke et al., 2016). Finally, LQM01 was able to prevent the neurological changes that cause SAP/JNK and $\mathrm{p} 38^{\mathrm{MAPK}}$ activation in adult life, preserving normal brain functions.

Several studies have attributed the long-term cognitive impairment and anxiety-like the behavior of septic mice to the to the brain inflammation (Chesnokova et al., 2016; Yin et al., 2017) that occurred during neonatal phase. A common feature of neonatal sepsis is the systemic induction of inflammatory mediators, which can disrupt the blood-brain barrier (BBB) and interact with the brain, thereby causing brain inflammation. Sepsis is associated with the exacerbated production of proinflammatory cytokines, such as TNF- $\alpha$, IL-1, IL- 6 , and IL- 
12 (Aikawa, 1996); paradoxically this severe inflammatory response is associated with the release of antiinflammatory cytokines, such as IL-10, which attempt to restore the immunological balance (Cohen, 2002; Park et al., 2018; Schulte et al., 2013). Ours findings corroborate with these findings, we describe that LPS cause a severe neuroinflammation in hippocampus of neonates. The brain cells showed increased proinflammatory cytokines production and activated inflammatory molecular pathway in the first's days after LPS administration. This neonatal neuroinflammation caused neurological disruption that provokes behavior impairment in adult life.

We, therefore, analyzed the effect of LQM01 on important inflammatory mediators in hippocampus of neonatal mice in the peak period of neuroinflammatory process induced by LPS (until $12 \mathrm{~h}$ ). LQM01 treatment induced a decrease in the pro-inflammatory cytokine's TNF- $\alpha$, IL-1 and IL-6 levels in hippocampus of 2-day old mice exposed to LPS, so mitigating the deleterious inflammatory damage produced by LPS. These data corroborate our hypothesis that LQM01 exerts a potential inhibitory effect on LPS-induced inflammatory responses in the neonatal sepsis mouse model. The dramatic change in the levels of several cytokines in the early stages in the LQM01 group highlighted its important role in the mitigation of long-term neurological deficit. Studies have been reported that downregulation on cytokines production, as well as in $\mathrm{NF} \kappa \mathrm{B}$ activation, decrease neuroinflammation and cognitive deficit in septic mice (Pan et al., 2018).

Next, we analyzed NFkB and COX-2 activation, factors that play pivotal roles in immune and inflammatory responses, including sepsis (Akira et al., 2006; Wright and Christman, 2003; Zhang et al., 2012). NFkB is a nuclear transcription factor that regulates the genes of pro-inflammatory cytokines, including IL-1 $\beta$, IL-6, and TNF- $\alpha$, as well as upregulating the expression of COX-2 (Grilli et al., 1993; Ji et al., 2017). Additionally, $\mathrm{NF} \kappa \mathrm{B}$ activation has been positively correlated to mortality in a model of sepsis (O'Sullivan et al., 2009). LQM01 was able to suppress NFKB and COX-2 activation, reducing the inflammatory response unleashed by LPS administration and consequently decreasing the brain injuries. It is well known that NFkB and COX-2 play essential pathophysiologic roles in sepsis, with these proteins being important targets for anti-septic drugs (Hsu et al., 2013).

$\mathrm{NF} \kappa \mathrm{B}$ is a nuclear transcription factor that regulates the inflammatory process (Grilli et al., 1993; Ji et al., 2017 ). This transcription factor is present in inactive form in the cytosol of cells, being complexed with NFKBia ( Kim et al., 2016). The inflammatory stimuli activate NFkB by IkB kinases (IKK)-induced phosphorylation and consequently the release of NFxBia from its complex (Kim et al., 2014), allowing the nuclear translocation of p65 subunits (Shafik et al., 2015). However, phosphorylation events also contribute to activation and nuclear translocation of NFkB. The cytoplasmatic phosphorylation of p65 subunits at Ser 536 residue (Mattioli et al., 2004) enhance p65 transcriptional activity and DNA binding (Viatour et al., 2005), contributing to activation of NFkB. Moreover, this posttranslational event reduces the ability of NFkBia to bind p65 subunits ( Bohuslav et al., 2004). So, the increased of phosphorylation of Ser 536 residue of NFKB contributed to its nuclear translocation and consequently the activation of the inflammatory mediator's transcription.

Evidence suggests that the upregulation of the MAPK signaling pathway is also an important factor related to the inflammation process associated with sepsis establishment (Chang et al., 2018). p38 ${ }^{\mathrm{MAPK}}$ is expressed at relatively high levels in the brain and plays a critical role in the increase of pro-inflammatory cytokine levels 
during inflammatory period. In addition, $\mathrm{p} 38^{\mathrm{MAPK}}$ has been implicated in positively regulating the expression of several genes involved in the acute inflammatory phase response, such as TNF- $\alpha$, IL- 6 and other inducible enzymes (O'Sullivan et al., 2009; Smith et al., 2006). Therefore, the inhibition of p38 MAPK in the early phase of sepsis produced by LQM01 treatment can contribute to the broad anti-inflammatory effects demonstrated by this aminoguanidine, so contributing to the anti-septic profile of LQM01. Yousif et al. (2018) show that reduction of pro-inflammatory cytokines through downregulation of the $\mathrm{p} 38^{\mathrm{MAPK}}$ pathways attenuate sepsis dysfunction, corroborating our results.

Our study also provided evidence that LQM01 decreased the pro-inflammatory reaction in the CNS characterized by mitigation of microglia activation caused by neonatal exposure to LPS. Microglia activation is essential for the development of brain inflammation and memory impairment after systemic inflammation ( Michels et al., 2015). The activation of microglia in the inflammatory response can be deleterious for surrounding neurons and glial cells through the production of inflammatory cytokines (Harry and Kraft, 2012). These structural and inflammatory changes may explain some of the CNS abnormalities observed in humans after neonatal sepsis (Alshaikh et al., 2013; Kidokoro et al., 2013). The reduction of microglia activation induced by LQM01 caused a decrease in brain inflammation and consequently protected neural cells from inflammatory damage, corroborating previous results of our study, which seemed to be related to a protective effect in the hippocampus of neonatal pups.

It is also thought that the inhibition of microglia activation can modulate major events in the progression of sepsis, such as oxidative stress. Studies have demonstrated that oxidative stress is also associated with longterm cognitive impairment (Biff et al., 2013; Schwalm et al., 2014). Thus, we analyzed the effect of LQM01 on redox homeostasis, since Sandes et al. (2018) reported that LQM01 has antioxidant properties related to the modulation of inflammatory and neurogenic pain. The results showed that this compound reduces lipoperoxidation in hippocampus of young septic mice. Increased lipid peroxidation can disrupt the normal function of biological membranes (Avery, 2011) and is often considered a marker of the oxidative damage associated with neurological diseases and sepsis (Catalão et al., 2017; Kemp et al., 2016; Niki et al., 2005). The reduction of oxidative stress by LQM01 during inflammatory and oxidative period of septic event could protect brain from permanent injury.

Additionally, our study also examined the protection offered to the integrity of the vascular barrier by LQM01. Maintenance of the barrier integrity is emerging as an important therapeutic strategy to prevent brain damage (Kwak et al., 2014). Peripheral LPS induces its effects by altering BBB permeability and function, acting on LPS receptors located outside the BBB (Banks and Erickson, 2010; Banks and Robinson, 2010), or by activating brain microvascular endothelial cells through the stimulation of downstream signaling pathways (Grab et al., 2011). It is probable that treatment with LQM01 preserves BBB integrity by decreasing receptor stimulation or through the activation of brain microvascular endothelial cells. The LQM01 response diminished the levels of toxic molecules in the brain, reducing the brain damage and consequently attenuating the neurologic deficit.

In summary, the findings of this study reveal a new activity of LQM01 as an innovative anti-septic agent. LQM01 attenuated inflammatory reactions in an LPS-challenged neonatal sepsis mice model through MAPK 
and NFkB signaling pathway and microglia activation suppression, decreasing pro-inflammatory cytokine release and COX-2 expression. The inhibition of inflammatory response in the neonatal phase avoided the cognitive impairment caused by LPS and the anxiety-like behavior observed in septic mice. Fig. 10 outlines the possible mechanisms of action of LQM01 in LPS-challenged neonatal sepsis mice, and also offers additional targets for studying the therapeutic potential of LQM01 in treating inflammatory diseases.

alt-text: Fig. 10

Fig. 10

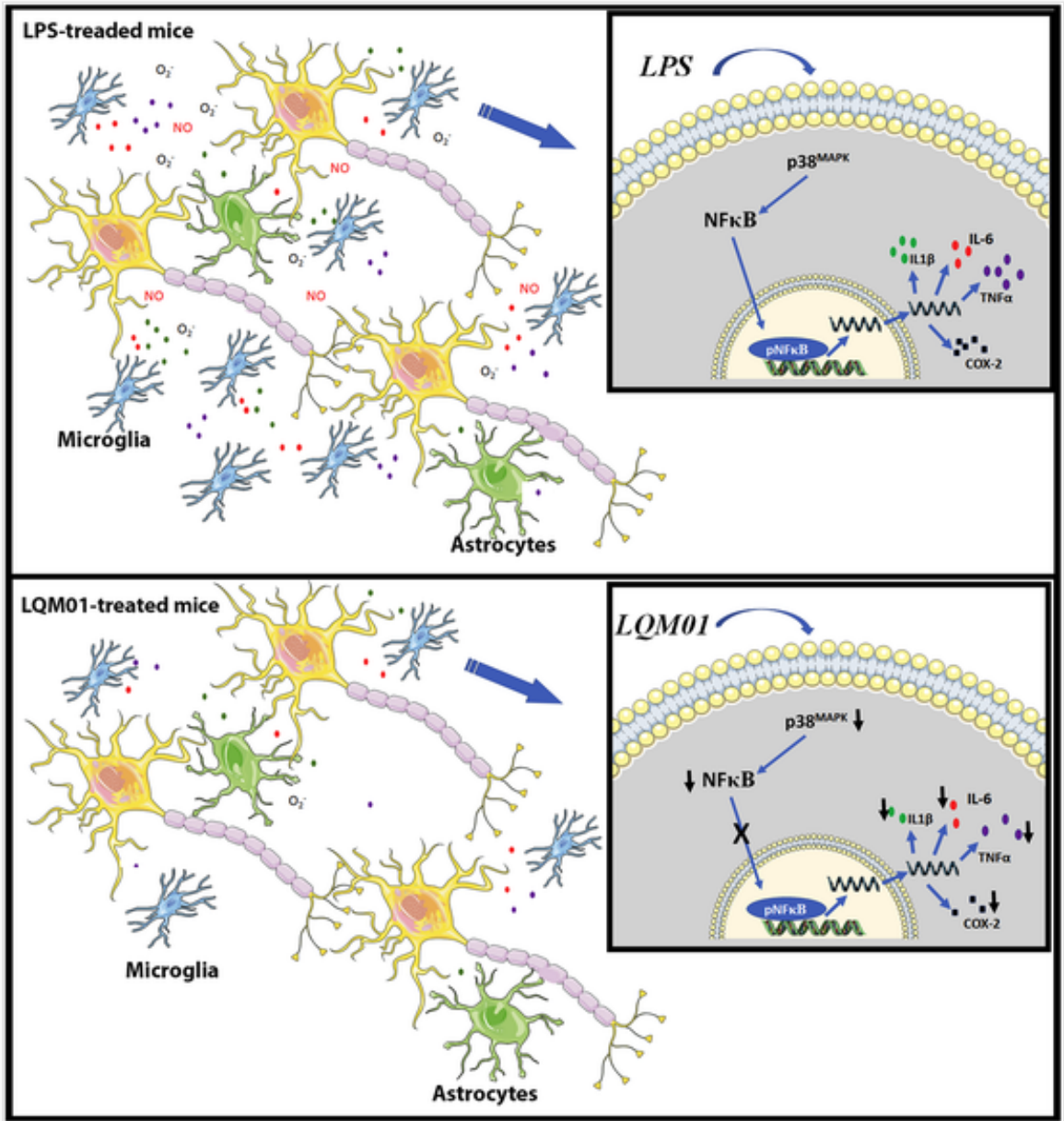

Proposed mechanisms of action of LQM01 in LPS-challenged neonatal sepsis mice. TNF- $\alpha$, purple circle; IL1 $\beta$, green circle; IL6 , red circle; COX-2, black squares. (For interpretation of the references to colour in this figure legend, the reader is referred to the Web version of this article.)

Despite the compelling evidence of the substantial anti-septic profile of LQM01, the lack of information on potential toxicity, pharmacokinetic parameters, and clinical studies means that further studies in these areas are necessary to develop this aminoguanidine as a possible new drug to use in the treatment of sepsis.

\section{Compliance with ethical standards}


All procedures performed in studies involving animals were in accordance with the Guidelines on Ethical Standards for the Investigation of Experimental Pain in Animals (Zimmermann, 1983) and were approved by the Animal Care and Use Committee of the Federal University of Sergipe.

\section{Declaration of competing interestCOI}

The authors declare no conflicts of interest.

\section{CRediT authorship contribution statement}

Luana Heimfarth: Conceptualization, Methodology, Formal analysis, Investigation, Writing - original draft, Writing - review \& editing, Visualization, Project administration. Alexandra Maria Santos Carvalho: Methodology, Formal analysis, Investigation. Jullyana de Souza Siqueira Quintans: Conceptualization, Validation, Writing - original draft, Data curation. Erik Willyame Menezes Pereira: Methodology, Formal analysis, Investigation. Natália Teles Lima: Methodology, Formal analysis, Investigation. Mikaella Tuanny Bezerra Carvalho: Methodology, Formal analysis, Investigation. Rosana de Souza Siqueira Barreto: Validation, Formal analysis, Investigation, Writing - original draft. José Cláudio Fonseca Moreira: Supervision, Project administration, Funding acquisition, Writing - original draft. Edeildo F. da Silva-Júnior: Resources, Investigation, Writing - original draft. Martine Schmitt: Supervision, Project administration, Writing - original draft. Jean-Jacques Bourguignon: Supervision, Project administration, Writing - original draft. Thiago M. de Aquino: Resources, Methodology, Investigation, Writing - original draft. João X. de Araújo-Júnior: Resources, Investigation, Writing - original draft. Lucindo J. Quintans-Júnior: Conceptualization, Writing - original draft, Writing - review \& editing, Resources, Supervision, Project administration, Funding acquisition.

\section{Acknowledgements}

This study was supported by Fundação de Apoio à Pesquisa e a Inovação Tecnológica do Estado de Sergipe, FAPITEC-SE (Edital 01/2016 - PPDOC), Conselho Nacional de Desenvolvimento Científico e Tecnológico, CNPq (304112/2017-8), Coordenação de Aperfeiçoamento de Pessoal de Nível Superior, CAPES (EDITAL CAPES/FAPITEC/SE N ${ }^{\circ}$ 10/2016) and Financiadora de Estudos e Projetos, FINEP (CT-INFRA FINEP 2014), all agencies from Brazil.

\section{References}

The corrections made in this section will be reviewed and approved by journal production editor.

Adén, U., Favrais, G., Plaisant, F., Winerdal, M., Felderhoff-Mueser, U., Lampa, J., Lelièvre, V., Gressens, P., 2010. Systemic inflammation sensitizes the neonatal brain to excitotoxicity through a pro-/anti-inflammatory imbalance: key role of TNFalpha pathway and protection by etanercept. Brain Behav. Immun. 24, 747-758. doi:10.1016/j.bbi.2009.10.010. 
Aikawa, N., 1996. Cytokine storm in the pathogenesis of multiple organ dysfunction syndrome associated with surgical insults. Nihon Geka Gakkai Zasshi 97, 771-777.

Akira, S., Uematsu, S., Takeuchi, O., 2006. Pathogen recognition and innate immunity. Cell 124, 783801. doi:10.1016/j.cell.2006.02.015.

Alden, K.J., Motew, S.J., Sharma, A.C., Ferguson, J.L., 1998. Effect of aminoguanidine on plasma nitric oxide by-products and blood flow during chronic peritoneal sepsis. Shock 9, 289-295.

Alshaikh, B., Yusuf, K., Sauve, R., 2013. Neurodevelopmental outcomes of very low birth weight infants with neonatal sepsis: systematic review and meta-analysis. J. Perinatol.: Off. J. Calif. Perinat. Assoc. 33, 558-564. doi:10.1038/jp.2012.167.

Amtmann, E., Zöller, M., Schilling, G., 2000. Neutral sphingomyelinase-inhibiting guanidines prevent herpes simplex virus-1 replication. Drugs Exp. Clin. Res. 26, 57-65.

Antonio, C.B., Betti, A.H., Herzfeldt, V., Barreiro, E.J., Fraga, C.A.M., Rates, S.M.K., 2016. LASSBio579, a prototype antipsychotic drug, and clozapine are effective in novel object recognition task, a recognition memory model. Behav. Pharmacol. doi:10.1097/FBP.0000000000000200.

Avery, S.V., 2011. Molecular targets of oxidative stress. Biochem. J. 434, 201-210. doi:10.1042/BJ20101695.

Bajčetić, M., Spasić, S., Spasojević, I., 2014. Redox therapy in neonatal sepsis: reasons, targets, strategy, and agents. Shock 42, 179-184. doi:10.1097/SHK.0000000000000198.

Bakhuizen, S.E., de Haan, T.R., Teune, M.J., van Wassenaer-Leemhuis, A.G., van der Heyden, J.L., van der Ham, D.P., Mol, B.W.J., 2014. Meta-analysis shows that infants who have suffered neonatal sepsis face an increased risk of mortality and severe complications. Acta Paediatr. 103, 1211-1218. Oslo, Norway: 1992. doi:10.1111/apa.12764.

Banks, W.A., Erickson, M.A., 2010. The blood-brain barrier and immune function and dysfunction. Neurobiol. Dis. 37, 26-32. doi:10.1016/j.nbd.2009.07.031.

Banks, W.A., Robinson, S.M., 2010. Minimal penetration of lipopolysaccharide across the murine blood-brain barrier. Brain Behav. Immun. 24, 102-109. doi:10.1016/j.bbi.2009.09.001.

Barichello, T., Sayana, P., Giridharan, V.V., Arumanayagam, A.S., Narendran, B., Della Giustina, A., Petronilho, F., Quevedo, J., Dal-Pizzol, F., 2018. Long-term cognitive outcomes after sepsis: a translational systematic review. Mol. Neurobiol. doi:10.1007/s12035-018-1048-2.

Bersani, I., Auriti, C., Ronchetti, M.P., Prencipe, G., Gazzolo, D., Dotta, A., 2015. Use of early biomarkers in neonatal brain damage and sepsis: state of the art and future perspectives. BioMed Res. Int. 253520. 2015. doi:10.1155/2015/253520. 
Biff, D., Petronilho, F., Constantino, L., Vuolo, F., Zamora-Berridi, G.J., Dall'Igna, D.M., Comim, C.M., Quevedo, J., Kapczinski, F., Dal-Pizzol, F., 2013. Correlation of acute phase inflammatory and oxidative markers with long-term cognitive impairment in sepsis survivors rats. Shock 40, 45-48. doi:10.1097/SHK.0b013e3182959cfa.

Bohuslav, J., Chen, L.-F., Kwon, H., Mu, Y., Greene, W.C., 2004. p53 induces NF-kappaB activation by an IkappaB kinase-independent mechanism involving phosphorylation of p65 by ribosomal S6 kinase 1. J. Biol. Chem. 279, 26115-26125. doi:10.1074/jbc.M313509200.

Bone, R.C., Balk, R.A., Cerra, F.B., Dellinger, R.P., Fein, A.M., Knaus, W.A., Schein, R.M., Sibbald, W.J., 1992. Definitions for sepsis and organ failure and guidelines for the use of innovative therapies in sepsis. In: The ACCP/SCCM Consensus Conference Committee. American College of Chest Physicians/Society of Critical Care Medicine, pp. 1644-1655. Chest 101.

Bradford, M.M., 1976. A rapid and sensitive method for the quantitation of microgram quantities of protein utilizing the principle of protein-dye binding. Anal. Biochem. 72, 248-254.

Buchheit, K.H., Gamse, R., Giger, R., Hoyer, D., Klein, F., Klöppner, E., Pfannkuche, H.J., Mattes, H., 1995. The serotonin 5-HT4 receptor. 2. Structure-activity studies of the indole carbazimidamide class of agonists. J. Med. Chem. 38, 2331-2338.

Burnes, L. a, Kolker, S.J., Danielson, J.F., Walder, R.Y., Sluka, K. a, 2008. Enhanced muscle fatigue occurs in male but not female ASIC3-/- mice. Am. J. Physiol. Regul. Integr. Comp. Physiol. 294, R1347-R1355. doi:10.1152/ajpregu.00687.2007.

Burnham, J.P., Lane, M.A., Kollef, M.H., 2015. Impact of sepsis classification and multidrug-resistance status on outcome among patients treated with appropriate therapy. Crit. Care Med. 43, 1580-1586. doi:10.1097/CCM.0000000000001013.

Camacho-Gonzalez, A., Spearman, P.W., Stoll, B.J., 2013. Neonatal infectious diseases: evaluation of neonatal sepsis. Pediatr. Clin. N. Am. 60, 367-389. doi:10.1016/j.pcl.2012.12.003.

Cardoso, F.L., Herz, J., Fernandes, A., Rocha, J., Sepodes, B., Brito, M.A., McGavern, D.B., Brites, D., 2015. In: Systemic Inflammation in Early Neonatal Mice Induces Transient and Lasting Neurodegenerative Effects, 12. p. 82.

Cardoso, F.L., Herz, J., Fernandes, A., Rocha, J., Sepodes, B., Brito, M.A., McGavern, D.B., Brites, D., 2015. In: Systemic Inflammation in Early Neonatal Mice Induces Transient and Lasting Neurodegenerative Effects, 12. p. 82.

Catalão, C.H.R., Santos-Júnior, N.N., da Costa, L.H.A., Souza, A.O., Alberici, L.C., Rocha, M.J.A., 2017. Brain oxidative stress during experimental sepsis is attenuated by simvastatin administration. Mol. Neurobiol. 54, 7008-7018. doi:10.1007/s12035-016-0218-3. 
Chang, C.-H., Hsu, C.-C., Lee, A.-S., Wang, S.-W., Lin, K.-T., Chang, W.-L., Peng, H.-C., Huang, W.C., Chung, C.-H., 2018. 4-Acetylantroquinonol B inhibits lipopolysaccharide-induced cytokine release and alleviates sepsis through of MAPK and NF kappa B suppression. BMC Complement Altern. Med. 18. doi:10.1186/s12906-018-2172-2.

Chesnokova, V., Pechnick, R.N., Wawrowsky, K., 2016. Chronic peripheral inflammation, hippocampal neurogenesis, and behavior. Brain Behav. Immun. 58, 1-8. doi:10.1016/j.bbi.2016.01.017.

Cohen, J., 2002. The immunopathogenesis of sepsis. Nature 420, 885-891. doi:10.1038/nature01326.

Comim, C.M., Bussmann, R.M., Simão, S.R., Ventura, L., Freiberger, V., Patrício, J.J., Palmas, D., Mendonça, B.P., Cassol, O.J., Quevedo, J., 2016. Experimental neonatal sepsis causes long-term cognitive impairment. Mol. Neurobiol. 53, 5928-5934. doi:10.1007/s12035-015-9495-5.

Corrêa, S.A.L., Eales, K.L., 2012. The role of p38 MAPK and its substrates in neuronal plasticity and neurodegenerative disease. J. Signal Transduct. 2012. doi:10.1155/2012/649079.

Costa, C.D.F., 2017. Atividade vasorelaxante e anti-hipertensiva de LQM01, um novo derivado aminoganidínico, em ratos espontaneamente hipertensos (Tese). Universidade Federal de Alagoas, Alagoas, Brasil.

Dammann, O., Leviton, A., 1997. Maternal intrauterine infection, cytokines, and brain damage in the preterm newborn. Pediatr. Res. 42, 1-8. doi:10.1203/00006450-199707000-00001.

Draper, H.H., Hadley, M., 1990. Malondialdehyde determination as index of lipid peroxidation. Methods Enzymol. 186, 421-431.

Dunham, N.W., Miya, T.S., 1957. A note on a simple apparatus for detecting neurological deficit in rats and mice. J. Am. Pharm. Assoc. 46, 208-209.

Ellman, G.L., 1959. Tissue sulfhydryl groups. Arch. Biochem. Biophys. 82, 70-77.

A. Ennaceur, J. Delacour. A new one - trial test for neurobiological studies of memory in rats . 1 " Behavioral data. Behavioural Brain Research. https://doi.org/10.1016/0166-4328(88)90157-X, 1988.

Fink, M.P., Warren, H.S., 2014. Strategies to improve drug development for sepsis. Nat. Rev. Drug Discov. 13, 741-758. doi:10.1038/nrd4368.

França, P.H.B., Da Silva-Júnior, E.F., Aquino, P.G.V., Santana, A.E.G., Ferro, J.N.S., De Oliveira Barreto, E., Do Ó Pessoa, C., Meira, A.S., De Aquino, T.M., Alexandre-Moreira, M.S., Schmitt, M., De Araújo-Júnior, J.X., 2016. Preliminary in vitro evaluation of the anti-proliferative activity of guanylhydrazone derivatives. Acta Pharm. 66, 129-137. doi:10.1515/acph-2016-0015.

Fujikawa, F., Yamashita, I., Seno, T., Sasaki, M., Naito, M., 1966. [Studies on chemotherapeutics for Mycobacterium tuberculosis. XVII. Synthesis and antibacterial activity on Mycobacterium tuberculosis of indole-3-carboxaldehyde derivatives]. Yakugaku Zasshi: J. Pharm. Soc. Jpn. 86, 861-864. 
Ge, J.-F., Xu, Y.-Y., Qin, G., Pan, X.-Y., Cheng, J.-Q., Chen, F.-H., 2015. Nesfatin-1, a potent anorexic agent, decreases exploration and induces anxiety-like behavior in rats without altering learning or memory. Brain Res. 1629, 171-181. doi:10.1016/j.brainres.2015.10.027.

Gilhotra, N., Dhingra, D., 2009. Involvement of NO-cGMP pathway in anti-anxiety effect of aminoguanidine in stressed mice. Prog. Neuropsychopharmacol. Biol. Psychiatr. 33, 1502-1507. doi:10.1016/j.pnpbp.2009.08.012.

Goldenberg, N.M., Steinberg, B.E., Slutsky, A.S., Lee, W.L., 2011. Broken barriers: a new take on sepsis pathogenesis. Sci. Transl. Med. 3, 88ps25. doi:10.1126/scitranslmed.3002011.

Grab, D.J., Chakravorty, S.J., van der Heyde, H., Stins, M.F., 2011. How can microbial interactions with the blood-brain barrier modulate astroglial and neuronal function?. Cell Microbiol. 13, 1470-1478. doi:10.1111/j.1462-5822.2011.01661.x.

Grilli, M., Chiu, J.J., Lenardo, M.J., 1993. NF-kappa B and Rel: participants in a multiform transcriptional regulatory system. Int. Rev. Cytol. 143, 1-62.

Hagberg, H., Gressens, P., Mallard, C., 2012. Inflammation during fetal and neonatal life: implications for neurologic and neuropsychiatric disease in children and adults. Ann. Neurol. 71, 444-457. doi:10.1002/ana.22620.

Harry, G.J., Kraft, A.D., 2012. Microglia in the developing brain: a potential target with lifetime effects. Neurotoxicology (Little Rock) 33, 191-206. doi:10.1016/j.neuro.2012.01.012.

Hsu, C.-C., Lien, J.-C., Chang, C.-W., Chang, C.-H., Kuo, S.-C., Huang, T.-F., 2013. Yuwen02f1 suppresses LPS-induced endotoxemia and adjuvant-induced arthritis primarily through blockade of ROS formation, NFkB and MAPK activation. Biochem. Pharmacol. 85, 385-395. doi:10.1016/j.bcp.2012.11.002.

Ji, D., Zhou, Y., Li, S., Li, D., Chen, H., Xiong, Y., Zhang, Y., Xu, H., 2017. Anti-nociceptive effect of dexmedetomidine in a rat model of monoarthritis via suppression of the TLR4/NF- $\mathrm{BB}$ p65 pathway. Exp. Ther. Med. 14, 4910-4918. doi:10.3892/etm.2017.5196.

Kawai, H., Lazar, R., Metherate, R., 2007. Nicotinic control of axon excitability regulates thalamocortical transmission. Nat. Neurosci. 10, 1168-1175. doi:10.1038/nn1956.

Kemp, K., Redondo, J., Hares, K., Rice, C., Scolding, N., Wilkins, A., 2016. Oxidative injury in multiple sclerosis cerebellar grey matter. Brain Res. 1642, 452-460. doi:10.1016/j.brainres.2016.04.027.

Kidokoro, H., Neil, J.J., Inder, T.E., 2013. New MR imaging assessment tool to define brain abnormalities in very preterm infants at term. AJNR. Am. J. Neuroradiol. 34, 2208-2214. doi:10.3174/ajnr.A3521.

Kim, J.-S., Roberts, J.M., Bingman, W.E., Shao, L., Wang, J., Ittmann, M.M., Weigel, N.L., 2014. The prostate cancer TMPRSS2:ERG fusion synergizes with the vitamin D receptor (VDR) to induce 
CYP24A1 expression-limiting VDR signaling. Endocrinology 155, 3262-3273. doi:10.1210/en.20132019.

Kim, S.-J., Park, J.-S., Lee, D.-W., Lee, S.-M., 2016. Trichostatin A protects liver against septic injury through inhibiting toll-like receptor signaling. Biomol. Ther. 24, 387-394. doi:10.4062/biomolther.2015.176.

Kwak, S., Ku, S.-K., Han, M.-S., Bae, J.-S., 2014. Vascular barrier protective effects of baicalin, baicalein and wogonin in vitro and in vivo. Toxicol. Appl. Pharmacol. 281, 30-38. doi:10.1016/j.taap.2014.09.003.

Lawn, J.E., Cousens, S., Zupan, J., 2005. 4 million neonatal deaths: when? Where? Why?. Lancet 365, 891-900. doi:10.1016/S0140-6736(05)71048-5.

Lee, I., Neil, J.J., Huettner, P.C., Smyser, C.D., Rogers, C.E., Shimony, J.S., Kidokoro, H., Mysorekar, I.U., Inder, T.E., 2014. The impact of prenatal and neonatal infection on neurodevelopmental outcomes in very preterm infants. J. Perinatol.: Off. J. Calif. Perinat. Assoc. 34, 741-747. doi:10.1038/jp.2014.79.

Li, P., Chen, X.-R., Xu, F., Liu, C., Li, C., Liu, H., Wang, H., Sun, W., Sheng, Y.-H., Kong, X.-Q., 2018. Alamandine attenuates sepsis-associated cardiac dysfunction via inhibiting MAPKs signaling pathways. Life Sci. 206, 106-116. doi:10.1016/j.1fs.2018.04.010.

Li, Q., Song, W., Tian, Z., Wang, P., 2017. Aminoguanidine alleviated MMA-induced impairment of cognitive ability in rats by downregulating oxidative stress and inflammatory reaction. Neurotoxicology (Little Rock) 59, 121-130. doi:10.1016/j.neuro.2017.02.005.

Liu, L., Johnson, H.L., Cousens, S., Perin, J., Scott, S., Lawn, J.E., Rudan, I., Campbell, H., Cibulskis, R., Li, M., Mathers, C., Black, R.E., 2012. Global, regional, and national causes of child mortality: an updated systematic analysis for 2010 with time trends since 2000. Lancet 379, 2151-2161. doi:10.1016/S0140-6736(12)60560-1.

Lohner, R., Schwederski, M., Narath, C., Klein, J., Duerr, G.D., Torno, A., Knuefermann, P., Hoeft, A., Baumgarten, G., Meyer, R., Boehm, O., 2013. Toll-like receptor 9 promotes cardiac inflammation and heart failure during polymicrobial sepsis. Mediat. Inflamm. doi:10.1155/2013/261049.

Machado, J.R., Soave, D.F., da Silva, M.V., de Menezes, L.B., Etchebehere, R.M., Monteiro, M.L.G., dos, R., dos Reis, M.A., Corrêa, R.R.M., Celes, M.R.N., 2014. Neonatal sepsis and inflammatory mediators. Mediat. Inflamm. 269681. 2014. doi:10.1155/2014/269681.

Mårtensson, J., Bellomo, R., 2015. Sepsis-induced acute kidney injury. Crit. Care Clin. doi:10.1016/j.ccc.2015.06.003.

Mattioli, I., Sebald, A., Bucher, C., Charles, R.-P., Nakano, H., Doi, T., Kracht, M., Schmitz, M.L., 2004. Transient and selective NF-kappa B p65 serine 536 phosphorylation induced by $\mathrm{T}$ cell 
costimulation is mediated by I kappa B kinase beta and controls the kinetics of p65 nuclear import. J. Immunol. 172, 6336-6344. doi:10.4049/jimmunol.172.10.6336.

Meyer, O.A., Tilson, H.A., Byrd, W.C., Riley, M.T., 1979. A method for the routine assessment of foreand hindlimb grip strength of rats and mice. Neurobehav. Toxicol. 1, 233-236.

Michels, M., Vieira, A.S., Vuolo, F., Zapelini, H.G., Mendonça, B., Mina, F., Dominguini, D., Steckert, A., Schuck, P.F., Quevedo, J., Petronilho, F., Dal-Pizzol, F., 2015. The role of microglia activation in the development of sepsis-induced long-term cognitive impairment. Brain Behav. Immun. 43, 54-59. doi:10.1016/j.bbi.2014.07.002.

Nadeau, C.A., Dietrich, K., Wilkinson, C.M., Crawford, A.M., George, G.N., Nichol, H., Nichol, F., 2018. Prolonged blood-brain barrier injury occurs after experimental intracerebral hemorrhage and is not acutely associated with additional bleeding. Transl. Stroke Res..

Natarajan, K., Abraham, P., Kota, R., Selvakumar, D., 2017. Aminoguanidine pretreatment prevents methotrexate-induced small intestinal injury in the rat by attenuating nitrosative stress and restoring the activities of vital mitochondrial enzymes. J. Basic Clin. Physiol. Pharmacol. 28, 239-247. doi:10.1515/jbcpp-2016-0099.

Niki, E., Yoshida, Y., Saito, Y., Noguchi, N., 2005. Lipid peroxidation: mechanisms, inhibition, and biological effects. Biochem. Biophys. Res. Commun. 338, 668-676. doi:10.1016/j.bbrc.2005.08.072.

O’Sullivan, A.W., Wang, J.H., Redmond, H.P., 2009. NF-kappaB and p38 MAPK inhibition improve survival in endotoxin shock and in a cecal ligation and puncture model of sepsis in combination with antibiotic therapy. J. Surg. Res. 152, 46-53. doi:10.1016/j.jss.2008.04.030.

Pagnussat, N., Almeida, A.S., Marques, D.M., Nunes, F., Chenet, G.C., Botton, P.H.S., Mioranzza, S., Loss, C.M., Cunha, R.A., Porciúncula, L.O., 2015. Adenosine A(2A) receptors are necessary and sufficient to trigger memory impairment in adult mice. Br. J. Pharmacol. 172, 3831-3845. doi:10.1111/bph.13180.

Pan, S., Wu, Y., Pei, L., Li, S., Song, L., Xia, H., Wang, Y., Yu, Y., Yang, X., Shu, H., Zhang, J., Yuan, S., Shang, Y., 2018. BML-111 reduces neuroinflammation and cognitive impairment in mice with sepsis via the SIRT1/NF-кB signaling pathway. Front. Cell. Neurosci. 12. doi:10.3389/fncel.2018.00267.

Park, H.J., Lee, S.J., Cho, J., Gharbi, A., Han, H.D., Kang, T.H., Kim, Y., Lee, Y., Park, W.S., Jung, I.D., Park, Y.-M., 2018. Tamarixetin exhibits anti-inflammatory activity and prevents bacterial sepsis by increasing IL-10 production. J. Nat. Prod. 81, 1435-1443. doi:10.1021/acs.jnatprod.8b00155.

Peng, Q., Deng, Z., Pan, H., Gu, L., Liu, O., Tang, Z., 2018. Mitogen-activated protein kinase signaling pathway in oral cancer. Oncol. Lett. 15, 1379-1388. doi:10.3892/ol.2017.7491.

Polito, A., Eischwald, F., Maho, A.-L., Polito, A., Azabou, E., Annane, D., Chrétien, F., Stevens, R.D., Carlier, R., Sharshar, T., 2013. Pattern of brain injury in the acute setting of human septic shock. Crit. 
Care 17, R204. doi:10.1186/cc12899.

Prasad, R.N., McKay, A.F., 1967. Acylation of guanidines and guanylhydrazones. Can. J. Chem. 45, 2247-2252. doi:10.1139/v67-362.

Prut, L., Belzung, C., 2003. The open field as a paradigm to measure the effects of drugs on anxiety-like behaviors: a review. Eur. J. Pharmacol. 463, 3-33.

Quintans-Júnior, L.J., Melo, M.S., De Sousa, D.P., Araujo, A.A.S., Onofre, A.C.S., Gelain, D.P., Gonçalves, J.C.R., Araújo, D.A.M., Almeida, J.R.G.S., Bonjardim, L.R., 2010. Antinociceptive effects of citronellal in formalin-, capsaicin-, and glutamate-induced orofacial nociception in rodents and its action on nerve excitability. J. Orofac. Pain 24, 305-312.

Raimondi, F., Ferrara, T., Maffucci, R., Milite, P., Del Buono, D., Santoro, P., Grimaldi, L.C.E.E., 2011. Neonatal sepsis: a difficult diagnostic challenge. Clin. Biochem. 44, 463-464. doi:10.1016/j.clinbiochem.2011.03.030.

Sakthivel, K.M., Guruvayoorappan, C., 2016. Acacia ferruginea inhibits inflammation by regulating inflammatory iNOS and COX-2. J. Immunotoxicol. 13, 127-135. doi:10.3109/1547691X.2015.1017625.

Sandes, S.M.S., Heimfarth, L., Brito, R.G., Santos, P.L., Gouveia, D.N., Carvalho, A.M.S., Quintans, J.S.S., da Silva-Júnior, E.F., de Aquino, T.M., França, P.H.B., de Araújo-Júnior, J.X., AlbuquerqueJúnior, R.L.C., Zengin, G., Schmitt, M., Bourguignon, J.-J., Quintans-Júnior, L.J., 2018. Evidence for the involvement of TNF- $\alpha$, IL-1 $\beta$ and IL-10 in the antinociceptive and anti-inflammatory effects of indole-3-guanylhydrazone hydrochloride, an aromatic aminoguanidine, in rodents. Chem. Biol. Interact. 286, 1-10. doi:10.1016/j.cbi.2018.02.026.

Schulte, W., Bernhagen, J., Bucala, R., 2013. Cytokines in sepsis: potent immunoregulators and potential therapeutic targets--an updated view. Mediat. Inflamm. 165974. 2013. doi:10.1155/2013/165974.

Schwalm, M.T., Pasquali, M., Miguel, S.P., Dos Santos, J.P.A., Vuolo, F., Comim, C.M., Petronilho, F., Quevedo, J., Gelain, D.P., Moreira, J.C.F., Ritter, C., Dal-Pizzol, F., 2014. Acute brain inflammation and oxidative damage are related to long-term cognitive deficits and markers of neurodegeneration in sepsissurvivor rats. Mol. Neurobiol. 49, 380-385. doi:10.1007/s12035-013-8526-3.

Shafik, N.M., Mohamed, D.A., Bedder, A.E., El-Gendy, A.M., 2015. Significance of tissue expression and serum levels of angiopoietin-like protein 4 in breast cancer progression: link to NF- $\mathrm{B} / \mathrm{P} 65$ activity and pro-inflammatory cytokines. Asian Pac. J. Cancer Prev. APJCP 16, 8579-8587. doi:10.7314/apjcp.2015.16.18.8579.

Smith, S.J., Fenwick, P.S., Nicholson, A.G., Kirschenbaum, F., Finney-Hayward, T.K., Higgins, L.S., Giembycz, M.A., Barnes, P.J., Donnelly, L.E., 2006. Inhibitory effect of p38 mitogen-activated protein 
kinase inhibitors on cytokine release from human macrophages. Br. J. Pharmacol. 149, 393-404. doi:10.1038/sj.bjp.0706885.

Soliman, M.M., 2014. Effects of aminoguanidine, a potent nitric oxide synthase inhibitor, on myocardial and organ structure in a rat model of hemorrhagic shock. J. Emergencies, Trauma, Shock 7, 190-195. doi:10.4103/0974-2700.136864.

Strunk, T., Inder, T., Wang, X., Burgner, D., Mallard, C., Levy, O., 2014. Infection-induced inflammation and cerebral injury in preterm infants. The Lancet. Infect. Dis. 14, 751-762. doi:10.1016/S1473-3099(14)70710-8.

Viatour, P., Merville, M.-P., Bours, V., Chariot, A., 2005. Phosphorylation of NF-kappaB and IkappaB proteins: implications in cancer and inflammation. Trends Biochem. Sci. 30, 43-52. doi:10.1016/j.tibs.2004.11.009.

Wefers, B., Hitz, C., Hölter, S.M., Trümbach, D., Hansen, J., Weber, P., Pütz, B., Deussing, J.M., de Angelis, M.H., Roenneberg, T., Zheng, F., Alzheimer, C., Silva, A., Wurst, W., Kühn, R., 2012. MAPK signaling determines anxiety in the juvenile mouse brain but depression-like behavior in adults. PLoS One 7, e35035. doi:10.1371/journal.pone.0035035.

Wright, J.G., Christman, J.W., 2003. The role of nuclear factor kappa B in the pathogenesis of pulmonary diseases: implications for therapy. Am. J. Respir. Med.: Drugs Devices Interv. 2, 211-219.

Yin, M., Chen, Y., Zheng, H., Pu, T., Marshall, C., Wu, T., Xiao, M., 2017. Assessment of mouse cognitive and anxiety-like behaviors and hippocampal inflammation following a repeated and intermittent paradoxical sleep deprivation procedure. Behav. Brain Res. 321, 69-78. doi:10.1016/j.bbr.2016.12.034.

Yousif, N.G., Hadi, N.R., Al-Amran, F., Zigam, Q.A., 2018. Cardioprotective effects of irbesartan in polymicrobial sepsis : the role of the p38MAPK/NF-кB signaling pathway. Herz 43, 140-145. doi:10.1007/s00059-017-4537-6.

Zarbock, A., Gomez, H., Kellum, J.A., 2014. Sepsis-induced acute kidney injury revisited: pathophysiology, prevention and future therapies. Curr. Opin. Crit. Care doi:10.1097/MCC.0000000000000153.

Zea-Vera, A., Ochoa, T.J., 2015. Challenges in the diagnosis and management of neonatal sepsis. J. Trop. Pediatr. 61, 1-13. doi:10.1093/tropej/fmu079.

Zeke, A., Misheva, M., Reményi, A., Bogoyevitch, M.A., 2016. JNK signaling: regulation and functions based on complex protein-protein partnerships. Microbiol. Mol. Biol. Rev.: MMBR (Microbiol. Mol. Biol. Rev.) 80, 793-835. doi:10.1128/MMBR.00043-14.

Zhang, N., Feng, H., Liao, H.-H., Chen, S., Yang, Z., Deng, W., Tang, Q.-Z., 2018. Myricetin attenuated LPS induced cardiac injury in vivo and in vitro. Phytother Res.: PTR 32, 459-470. 
doi:10.1002/ptr.5989.

Zhang, N., Zhang, L., Feng, L., Yao, L., 2018. Cananga odorata essential oil reverses the anxiety induced by 1-(3-chlorophenyl) piperazine through regulating the MAPK pathway and serotonin system in mice. J. Ethnopharmacol. 219, 23-30. doi:10.1016/j.jep.2018.03.013.

Zhang, Y., Wu, Y., Li, W., Zhou, C., Lu, F., Gao, T., Liu, Y., Cao, J., Zhang, Y., Zhou, C., 2012. Ketamine inhibits lipopolysaccharide-induced astrocytes activation by suppressing TLR4/NF- $\mathrm{B}$ pathway. Cell. Physiol. Biochem. 30, 609-617. doi:10.1159/000341442.

Zimmermann, M., 1983. Ethical guidelines for investigations of experimental pain in conscious animals. Pain 16, 109-110.

Zou, P., Ji, H.-M., Ding, X.-M., Zhen, Z.-G., Zhang, X., Nie, X., Xue, L., 2018. Protective effect of isoliquiritigenin against cerebral injury in septic mice via attenuation of NF- $\mathrm{B}$. Inflammopharmacology.

\section{Graphical abstract}

alt-text: Image 1

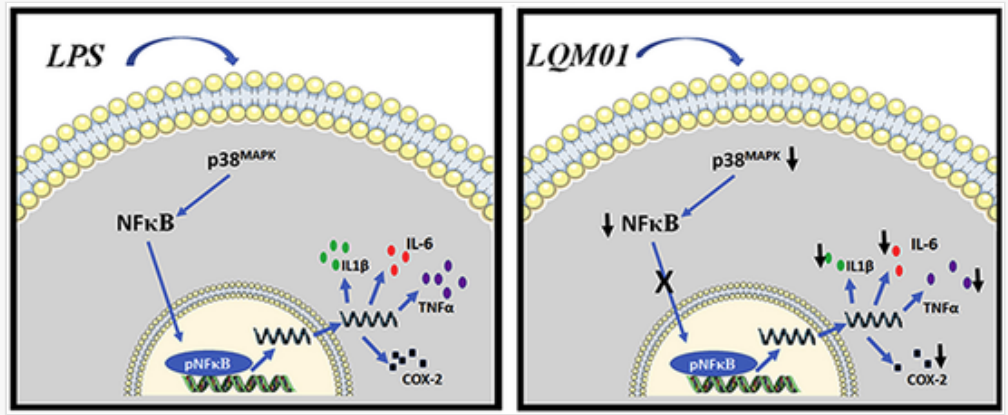

\section{Highlights}

- LQM01 exposure during the neonatal period reduces anxiety-like behavior caused by LPS.

- LQM01 exposure during the neonatal period reduces cognitive impairment caused LPS.

- LQM01 decrease neuroinflammation caused by LPS exposure during neonate phase.

- LQM01 decreased NFkB, COX-2, MAPK activation in hippocampus of mice exposure to LPS.

- LQM01 decreased microglia activation an protect BBB from LPS toxicity. 


\section{Queries and Answers}

Query: Your article is registered as a regular item and is being processed for inclusion in a regular issue of the journal. If this is NOT correct and your article belongs to a Special Issue/Collection please contact n.bhaskaran@elsevier.com immediately prior to returning your corrections.

\section{Answer:}

Query: Please confirm that given names and surnames have been identified correctly and are presented in the desired order and please carefully verify the spelling of all authors' names.

\section{Answer:}

Query: Please confirm that the provided emails “luahei@yahoo.com.br, lucindojr@gmail.com” are the correct address for official communication, else provide an alternate e-mail address to replace the existing one, because private e-mail addresses should not be used in articles as the address for communication.

\section{Answer:}

Query: Please note that author's telephone/fax numbers are not published in Journal articles due to the fact that articles are available online and in print for many years, whereas telephone/fax numbers are changeable and therefore not reliable in the long term.

\section{Answer:}

Query: Have we correctly interpreted the following funding source(s) you cited in your article: Coordenação de Aperfeiçoamento de Pessoal de Nível Superior, CAPES; Financiadora de Estudos e Projetos, FINEP; Conselho Nacional de Desenvolvimento Científico e Tecnológico, CNPq; Fundação de Apoio à Pesquisa e a Inovação Tecnológica do Estado de Sergipe, FAPITEC-SE?

\section{Answer:}

